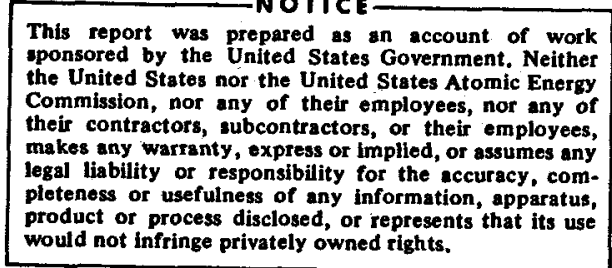

ORNL-TM-4322

Contract No. W-7405-eng-26

\title{
THE EXREM III COMPUTER CODE FOR ESTIMATING EXTERNAL RADIATION DOSES TO POPULATIONS FROM ENVIRONMENTAL RELEASES
}

\author{
D. K. Trubey \\ Radiation Shielding Information Center \\ Neutron Physics Division \\ S. V. Kaye \\ Environmental Sciences Division
}

DECEMBER 1973

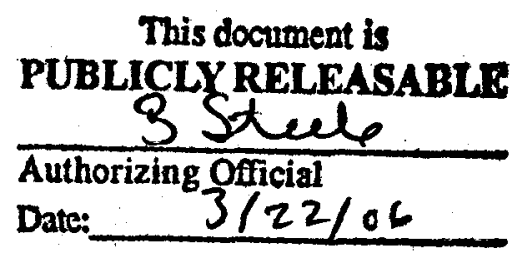

OAK RIDGE NATIONAL LABORATORY
Oak Ridge, Tennessee 37830
operated by
UNION CARBIDE CORPORATION
for the

U.S. ATOMIC ENERGY COMMISSION 


\section{DISCLAIMER}

This report was prepared as an account of work sponsored by an agency of the United States Government. Neither the United States Government nor any agency Thereof, nor any of their employees, makes any warranty, express or implied, or assumes any legal liability or responsibility for the accuracy, completeness, or usefulness of any information, apparatus, product, or process disclosed, or represents that its use would not infringe privately owned rights. Reference herein to any specific commercial product, process, or service by trade name, trademark, manufacturer, or otherwise does not necessarily constitute or imply its endorsement, recommendation, or favoring by the United States Government or any agency thereof. The views and opinions of authors expressed herein do not necessarily state or reflect those of the United States Government or any agency thereof. 


\section{DISCLAIMER}

Portions of this document may be illegible in electronic image products. Images are produced from the best available original document. 
CONTENTS

Page

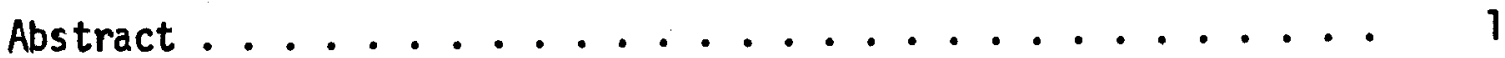

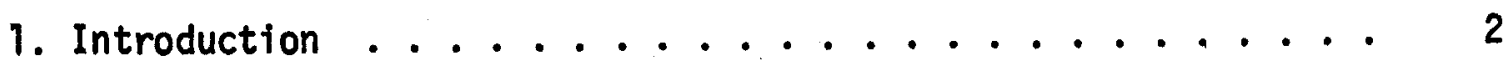

2. Estimating External Dose Equivalents .......... 2

2.1 Dose Equivalent Models ............. 2

2.2 Dose-Rate Factors .............. . 4

2.2.1 Beta and Gamma Rays .............. 4

2.2.2 Positrons and Electrons .......... . . 6

2.3 Calculation of the Concentration .......... 6

2.4 Calculation of the Accumulated Concentration ...... 11

3. The Computer Code ................. 13

3.1 The Computer Solution .............. 13

3.2 Special Calculations and Assumptions ........ 13

3.3 Description of Subroutines ........... 16

3.3.1 Overview .................... 16

3.3.2 Variable Dimensioning ........... 17

3.4 Definition of Program Variables ........... 19

3.5 Description of Input ............... 27

3.5.1 Input Categories .............. 27

3.5.2 Description of Each Group ........... 28 28

3.5.3 Input Summary .............. 38

4. Acknowledgments ................. 40

References ....................... 42

Appendix A ........................... 45

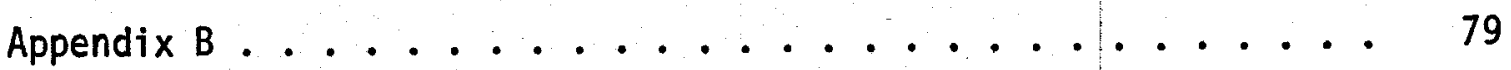


THE EXREM III COMPUTER CODE FOR ESTIMATING EXTERNAL RADIATION DOSES TO POPULATIONS FROM ENVIRONMENTAL RELEASES

D. K. Trubey and S. V. Kaye

ABSTRACT

EXREM III is a computer code to estimate the dose equivalent rate and the total dose equivalent from beta, positron, electron, and gamma radiation resulting from submersion in contaminated water, submersion in contaminated air, and exposure to a contaminated surface. There can be more than one environmental release, and exposure can begin at any time after the first release. EXREM III considers contributions from environmental releases and from nuclide decay chains. For a particular problem the user may choose to calculate either the dose rates, or the total doses, or both for any of the three modes of exposure. A separate solution array is printed for each mode of exposure. EXREM III is a revised version of EXREM II which was available earlier. ${ }^{1}$ The principal revisions include treatment of positron and electron radiations, selection of nuclear data from a data base, variable dimensioning of large data arrays, and free field input.

The code is available from the Radiation Shielding Information Center. 


\section{INTRODUCTION}

The earlier revision of this computer code, EXREM II (see refs. 1 and 2), estimates the dose equivalent rate and the total dose equivalent from beta and gamma radiation resulting from submersion in contaminated water, submersion in contaminated air, and exposure to a contaminated surface. However, EXREM II can give underestimates for certain radionuclides since it does not consider contributions from positrons and conversion or Auger electrons. Thus, the computer code EXREM III, which considers these contributions, was developed.

The input format for EXREM III is essentially similar to that of EXREM II. However, the nuclear data available are handled as a data base and the remaining data as free form. There are also more options available in the new code, EXREM III.

This report, which is self-contained, is designed to acquaint the user with the capabilities of EXREM III and to serve as a reference manual for setting up the input data.

\section{ESTIMATING -EXTERNAL DOSE EQUIVALENTS}

\subsection{Dose Equivalent Models}

For each radionuclide, the code determines the dose equivalent rate and the total dose equivalent from beta, positron, electron, $x$, and gamma radiation resulting from submersion in contaminated water, submersion in contaminated air, and exposure to a contaminated surface. There can be more than one environmental release, and exposure can 
begin at any time after the first release. A quantity of a radionuclide may be present both from an environmental release and from the decay of another radionuclide.

The dose equivalent rate at time $t$, including the contribution from radionuclide chains, is denoted by

$$
\mathrm{DR}_{i p q \ell}(t)=C_{i p \ell}(t) D_{i q p}
$$

where

$$
\begin{aligned}
i= & \text { radionuclide index, } \\
q= & \text { radiation index ( } \beta \text { for beta radiation, } p \text { for } \\
& \text { positrons, e for electrons, } \gamma \text { for gamma radiation), } \\
p= & \text { exposure index ( } w \text { for water, a for air, } s \text { for } \\
& \text { surface), } \\
l= & \text { location index, } \\
C_{i p \ell}(t)= & \text { concentration }(\mu C i / c c \text { for } p=w \text { and } p=a, \\
& \mu C i / \mathrm{cm}^{2} \text { for } p=s \text { ) of the } i \text { th radionuclide } \\
& \text { for the pth mode of exposure at the } \ell \text { th } \\
& \text { location at time } t, \\
D_{i q p}= & \text { dose-rate factor }\left[\left(\frac{m r e m i c c}{\mu C i \cdot h r}\right)\right] \text { for } p=w \text { and } \\
& \left.p=a ;\left(\frac{m r e m \cdot m^{2}}{\mu C i \cdot h r}\right) \text { for } p=s\right], \text { and } \\
t= & \text { time }(h r) .
\end{aligned}
$$

The total dose equivalent from $t_{1}$ to $t_{2}$ is denoted by

$$
T_{i p q l}\left(t_{1}, t_{2}\right)=D_{i q p} \int_{t_{1}}^{t_{2}} C_{i p \ell}(t) d t
$$

where $t_{1}$ and $t_{2}$ are in hours. 


\subsection{Dose-Rate Factors}

2.2.1 Beta and Gamma Rays

The dose-rate factors (see ref. 3) are denoted by

$$
\begin{aligned}
& D_{i \beta W}=\frac{25.6}{24.0} \sum_{n=1}^{N_{B i}}\left(f_{\beta i n} \bar{E}_{\beta i n}\right), \\
& D_{i \gamma w}=\frac{51.2}{24.0} \sum_{n=1}^{N i}\left(f_{\gamma i n} E_{\gamma i n}\right), \\
& D_{i \gamma a}=\frac{29.2}{(24.0)\left(1.2 \times 10^{-3}\right)} \sum_{n=1}^{N_{\gamma i}}\left(f_{\gamma i n} E_{B i n}\right), \\
& D_{i \beta s}=1.07 \sum_{n=1}^{N_{B i}}\left\{v \alpha\left(F\left[C_{2} v, a(x)\right]+\exp [1-v a(x)]\right) f_{\beta i n} \bar{E}_{\beta i n}\right\}, \text { and } \\
& D_{i \gamma s}=827 B s \sum_{n=1}\left[\sigma_{i n} E_{1}\left(\sigma_{i n} x\right) f_{\gamma i n} E_{\gamma i n}\right],
\end{aligned}
$$

where

$$
\begin{aligned}
n= & \text { particle or photon index, } \\
N_{q i}= & \text { number of beta particles }(q=\beta) \text { or photons } \\
& (q=\gamma) \text { emitted by the ith radionuclide, } \\
f_{q i n}= & \text { abundance (dimensionless) of the nth beta particle } \\
& \text { or photon emitted by the ith radionuclide, } \\
\bar{E}_{B i n}= & \text { average energy (MeV) of the nth beta particle } \\
& \text { emitted by the ith radionuclide, } \\
E_{\gamma i n}= & \text { energy (MeV) of the nth photon emitted by } \\
& \text { the ith radionuclide, }
\end{aligned}
$$


$x=$ the distance $(\mathrm{cm})$ from the exposed individual to the contaminated surface,

$$
C=\left\{\begin{array}{l}
3.0, \quad E_{B \text { in }}<0.17, \\
2.0,0.17 \leq E_{B i n}<0.5, \\
1.5,0.5 \leq E_{B i n}<1.5, \\
1.0,1.5 \leq E_{B i n}
\end{array}\right.
$$

$E_{\text {Bin }}=$ maximum energy $(\mathrm{MeV})$ of the nth beta particle emitted by the ith radionuclide,

$$
\alpha=\left\{\begin{array}{l}
0.190, \quad E_{B \text { in }}<0.17, \\
0.260,0.17 \leq E_{B \text { in }}<0.5, \\
0.297,0.5 \leq E_{B \text { in }}<1.5 \\
0.333,1.5 \leq E_{B \text { in }}
\end{array}\right.
$$

$\nu=\left\{\begin{array}{l}\frac{(18.6)}{\left(E_{B i n}-0.036\right)^{1.37}} \text { if the radionuclide is not } S r-90, \\ \frac{(0.83)(18.6)}{\left(E_{B \text { in }}-0.036\right)^{1.37}} \text { if the radionuclide is } s r-90,\end{array}\right.$

$F[C, v, a(x)]=\left\{\begin{array}{l}c\left\{1+\ln \left[\frac{c}{v a(x)}\right]-\exp \left[1-\left(\frac{v a(x)}{c}\right)\right]\right\} \text { if } v a(x)<c, \\ 0 \text { if } v a(x) \geq c,\end{array}\right.$

$a(x)=$ distance from the contaminated surface multiplied by the density of air $\left(\mathrm{g} / \mathrm{cm}^{2}\right)$,

$\bar{E}_{B \text { in }}=0$ if $E_{\text {Bin }} \leq 0.036 \mathrm{MeV}$, 


$$
=1 / 3 E_{B \text { in }}(1-0.02 \sqrt{Z})\left(1+0.25 \sqrt{E_{B i n}}\right) \text { if } E_{B \text { in }}>0.036 \mathrm{MeV}
$$

$Z=$ atomic number

Bs = backscatter correction (dimensionless) for a body immersed in air,

$\sigma_{\text {in }}=$ linear energy absorption coefficient $\left(\mathrm{cm}^{-1}\right)\left[\sigma=\sigma\left(E_{\text {Yin }}\right)\right]$, and

$E_{p}(\sigma \cdot x)=$ Exponential integral (E-function) of the first order.

\subsubsection{Positrons and Electrons}

The dose rate factors for positrons and electrons are added to those for the beta rays. The average electron energy is taken to be the input energy; the average positron energy is calculated as follows:

$$
\bar{E}_{p i n}=1 / 3 E_{p i n}\left(1+0.25 \sqrt{E_{p i n}}\right) .
$$

\subsection{Calculation of the Concentration}

In general, nuclide decay chains may be characterized by steps, each represented by a particular nuclide. A particular nuclide will decay by various modes (e.g., $\beta$ decay), branching with certain probabilities (fractions or branching ratios) to other nuclides which may or may not be stable. Consider one possible sequence of decays from a starting nuclide to a stable one with a certain fraction, $f$, decaying to the next nuclide. This will be called a nuclide pathway. A decay chain may be resolved into one or more such pathways, each of which is represented as follows where each nuclide is numbered from 1 to s:

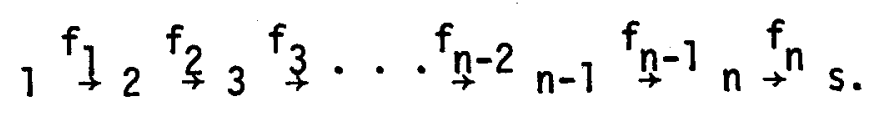


The following system of differential equations describes the decay process in the nuclide pathway (see refs, 4 and 5 ):

$$
\begin{aligned}
& \left\{\begin{array}{l}
\dot{N}_{1}(t)=-\lambda_{1} N_{1}(t) \\
\dot{N}_{2}(t)=-\lambda_{2} N_{2}(t)+\lambda_{1} f_{1} N_{1}(t) \\
\dot{N}_{3}(t)=-\lambda_{3} N_{3}(t)+\lambda_{2} f_{2} N_{2}(t) \\
\text { where }
\end{array}\right. \\
& \lambda_{i}=\text { decay constant }\left(\frac{1}{h r}\right) \text { of the ith radionuclide, } \\
& f_{j}=\text { fraction of nuclei of the } i \text { th radionuclide which decays } \\
& \text { to the } i+\text { st nuclide in the pathway, } \\
& t_{0}=\text { initial time }(h r) \text {, and } \\
& \dot{N}_{j}(t)=\frac{d N_{j}(t)}{d t}
\end{aligned}
$$


Now the activity is related to the number of disintegrations per hour by

$$
A_{i}(t)=\frac{\lambda_{i}}{k} N_{i}(t)
$$

where

$$
k=1.332 \times 10^{8} \frac{\mathrm{dis}}{\mathrm{hr} \cdot \mu \mathrm{Ci}}
$$

$A_{i}(t)=$ activity $(\mu C i)$ of the $i$ th radionuclide at time $t$.

For submersion in air $(p=a)$ or water $(p=w)$, let $C_{i p l}(t)=$ $A_{j}(t)$ per unit volume $\left(\frac{\text { dis }}{\mathrm{hr} \cdot \mu \mathrm{Ci} \cdot \mathrm{cm}^{3}}\right)$,

and for exposure to surface contamination $(p=s)$, let

$$
c_{i p \ell}(t)=A_{j}(t) \text { per unit surface area }\left(\frac{\text { dis }}{h r \cdot \mu C i \cdot \mathrm{cm}^{2}}\right) \text {. }
$$

Further, let

where

$$
\left\{\begin{aligned}
q_{i} & =\lambda_{i}, \\
s_{i} & =\lambda_{i+1} f_{i}, \\
c_{i p \ell}\left(t_{0}\right) & =A_{i}\left(t_{0}\right) g_{p i \ell}=c_{i p \ell}^{o}
\end{aligned}\right.
$$

$$
\begin{aligned}
g_{p i l}= & \text { location correction factor for the ith radionuclide, the } \\
& \text { pth mode of exposure, and the lth location. }
\end{aligned}
$$


9

Substituting Eqs. (11), (12); and (13) into Eqs. (9), one obtains

$$
\left\{\begin{array}{l}
\dot{c}_{1 p l}(t)=-q_{1} c_{1 p l}(t) \\
\dot{c}_{2 p l}(t)=-q_{2} c_{2 p l}(t)+s_{1} c_{1 p l}(t) \\
\dot{c}_{3 p l}(t)=-q_{3} c_{3 p l}(t)+s_{2} c_{2 p l}(t) \\
\dot{c}_{n p l}(t)=-q_{n} c_{n p l}(t)+s_{n-1} c_{(n-1) p l}(t) \\
c_{i p l}\left(t_{0}\right)=A_{j}\left(t_{0}\right) g_{p i l}=c_{i p l}^{0} \cdot i=1,2, \ldots, n .
\end{array}\right.
$$

The general solution to this system of equations is

$$
c_{i p m}(t)=\left\{\begin{array}{l}
c_{1 p m}^{0} e^{-q_{j} T}, i=1, \\
c_{i p m}^{0} e^{-q_{i} T}+T\left\{\sum_{k=1}^{i-1} c_{k p m}^{0}\left[\sum_{j=k}^{i-1} Y_{i j}(T) s_{j} \prod_{\substack{l=k \\
l \neq j}}^{i-1}\left(\frac{s_{l}}{q_{\ell}-q_{j}}\right)\right]\right\}, i>1,
\end{array}\right.
$$

where

$$
\begin{aligned}
& T=t-t_{0},
\end{aligned}
$$

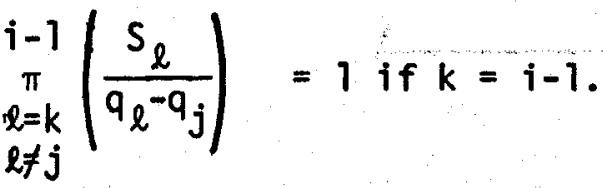

and

$$
Y_{i j}(T)= \begin{cases}\left\{\frac{1-\exp \left[-\left(q_{j}-q_{j}\right) T\right]}{\left(q_{j}-q_{j}\right) T}\right\} & e^{-q_{j} T}, \text { if } q_{j}>q_{j}, \\ \left\{\frac{1-\exp \left[-\left(q_{j}-q_{j}\right) T\right]}{\left(q_{j}-q_{j}\right) T}\right\} & e^{-q_{j} T}, \text { if } q_{j} \leq q_{j} .\end{cases}
$$


Thus for one environmental release, let $t_{0}$ equal the time of the release and $Y_{j}$ equal the yield vented by the release so that $c_{i p l}^{0}=$ $Y_{i} g_{p i l}$. Then $c_{i p l}(t)$ is given by Eq. (15). However, when $p=a$,

$$
c_{i a l}(t)=0 \text { if } t>t_{c}
$$

where $t_{c}=$ time $(h r)$ required for the radioactive cloud from the environmental release to pass the location.

The above procedure can be extended to estimate $C_{i p l}(t)$ when there exists more than one environmental release.

Next, consider a nuclide chain with branching and locate each pathway in the chain. The concentration for each radionuclide in each of the pathways of the chain can be solved by Eq. (15). For certain radionuclides, the contributions in some pathways must be added to the contributions from previous pathways. As an example, examine the following nuclide chain:

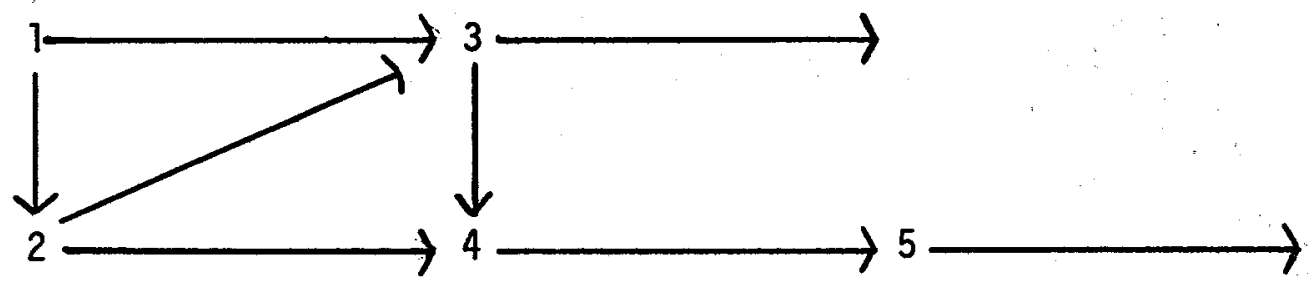

Radionuclides 3 and 5 decay into a stable nuclide. Each pathway in the nuclide chain is depicted below:

$$
\begin{aligned}
& 1+2 \rightarrow 3 \rightarrow 4+5 \\
& 1 \rightarrow 2+3 \rightarrow \\
& 1 \rightarrow 2 \rightarrow 504 \rightarrow 505 \rightarrow
\end{aligned}
$$




$$
\begin{aligned}
& 1 \rightarrow 503 \rightarrow 504 \rightarrow 505 \rightarrow \\
& 1 \rightarrow 3 \rightarrow
\end{aligned}
$$

For a particular pathway, 500 is added to the index of a radionuclide, as 503,504 , and 505 , to indicate that the contribution for the nuclide in this pathway is added to the contribution from previous pathways. Note that the partial activity of nuclide 3 can be calculated from either pathways 1 and 2 ; thus 500 is not added. The rest of the activity for nuclides 3,4 , and 5 is determined from pathway 4 . Pathway 5 does not add further activity to nuclide 3 ; thus 500 is not added.

\subsection{Calculation of the Accumulated Concentration}

To obtain an algorithm for approximating the integral in Eq. (2), consider the simpler case involving only one environmental release. Let

$$
I_{i p l}\left(t_{1}, t_{2}\right)=\int_{t_{1}}^{t_{2}} c_{i p l}(t) d t .
$$

When $p=a$, the upper limit of integration is actually the minimum of $t_{2}$ and $t_{c}$. By integrating the first equation in Eqs. (14), one obtains

$$
I_{1 p \ell}\left(t_{1}, t_{2}\right)=\frac{1}{q_{1}}\left[c_{1 p \ell}\left(t_{1}\right)-c_{1 p l}\left(t_{2}\right)\right] \text {. }
$$


By integrating the second equation in Eqs. (14) and combining the results with Eq. (19), one obtains

$$
I_{2 p l}\left(t_{1}, t_{2}\right)=\frac{1}{q_{2}}\left[c_{2 p l}\left(t_{1}\right)-c_{2 p l}\left(t_{2}\right)+s_{1} I_{1 p l}\left(t_{1}, t_{2}\right)\right],
$$

or in general

$$
I_{i p \ell}\left(t_{1}, t_{2}\right)=\frac{l}{q_{i}}\left[c_{i p \ell}\left(t_{1}\right)-c_{i p l}\left(t_{2}\right)+s_{i-1} I_{(i-1) p \ell}\left(t_{1}, t_{2}\right)\right] .
$$

Thus Eqs. (19) and (21) can be used to evaluate the integral in Eq. (2). If there is more than one environmental release, then let $\tau_{\mathbf{j}}$ denote the time of the $i$ th release. Define $k$ and $m$ so that $\tau_{k} \leq t_{1}<\tau_{k+1}$ and $\tau_{m}<t_{2} \leq \tau_{m+1}$. (If $k$ is the number of the final release, then $k+1$ will not exist, and if $M$ is the number of the final release, then $m+1$ will not exist.)

Then

$$
I_{i p \ell}\left(t_{1}, t_{2}\right)=I_{i p l}\left(t_{1}, \tau_{k+1}\right)+\sum_{n=k+1}^{m-1} I_{i p \ell}\left(\tau_{n}, \tau_{n+1}\right)+I_{i p \ell}\left(\tau_{m}, t_{2}\right) .
$$

Let

$$
c_{i p \ell n}^{0}=Y_{\text {in }} g_{\text {piln }} \text {. }
$$

For $i=1$, combine Eq. (22) with Eq. (19) to obtain

$$
I_{1 p \ell}\left(t_{1}, t_{2}\right)=\frac{1}{q_{1}} c_{1 p \ell}\left(t_{1}\right)+\sum_{n=k+1}^{m} c_{i p \ell n}^{0}-c_{1 p \ell}\left(t_{2}\right) .
$$


For $i>1$, combine Eq. (22) with Eq. (21) to obtain

$$
\begin{gathered}
I_{i p \ell}\left(t_{1}, t_{2}\right)=\frac{1}{q_{i}} c_{i p \ell}\left(t_{1}\right)+\sum_{n=k+1}^{m} c_{i p \ell n}^{o} \\
-c_{i p \ell}\left(t_{2}\right)+s_{i-1} I(i-1) p \ell\left(t_{1}, t_{2}\right)
\end{gathered}
$$

3. THE COMPUTER CODE

This section describes the computer code, EXREM III, written in FORTRAN IV for the IBM $36075 / 91$. The code can calculate the dose rates at a specified time and the total doses accumulated during a specified time interval resulting from submersion in contaminated water, submersion in contaminated air, and exposure to a contaminated surface. For each of the modes of exposure, the code performs the calculations for contamination from beta, positron, electron, and gamma or $x$-ray radiation. This section considers the computer solutions for the equations derived in Section 2.0, the special calculations and assumptions used by the code, a brief description of each subroutine, the definition of the program variables, and the input format.

\subsection{The Computer Solution}

The computer code EXREM III is programmed to solve Egs. (1) and (2) by using Eqs. (3) through (8), Eq. (15), and Eqs. (24) and (25).

\subsection{Special Calculations and Assumptions}

A term of the form

$$
f(x)=\frac{1-e^{-x}}{x}, x>0
$$


appears in Eq. (16). If $0<x \ll 1$, then a loss of significance can occur when the expression is evaluated on a digital computer. However, the expression can be expanded in a power series to obtain

$$
f(x)=1-\frac{x}{2 !}+\frac{x^{2}}{3 !}-\frac{x^{3}}{4 !}+\ldots .
$$

By choosing a sufficient number of terms, $f(x)$ can be evaluated accurately. The code uses this procedure to evaluate expressions containing terms of the form $f(x)$ when $0<x<0.01$.

The maximum energy of the nth beta particle emitted by the ith radionuclide, $E_{B i n}$, and the atomic number of the $i$ th radionuclide, $z_{i}$, are part of the data base input for EXREM III. The code uses these data to approximate the average beta energy, $\overline{\mathrm{E}}_{\beta \mathrm{Bn}}$, and positron energy, $\bar{E}_{\text {pin }}$, with the equations (see ref. 6 ):

$$
\begin{aligned}
& E_{\text {Bin }}=1 / 3 E_{\text {Bin }}\left(1-0.02 \sqrt{Z_{i}}\left(1+0.25 \sqrt{E_{\text {Bin }}}\right)\right. \\
& E_{\text {pin }}=1 / 3 E_{\text {pin }}\left(1+0.25 \sqrt{E_{\text {pin }}}\right) .
\end{aligned}
$$

A table containing values for the linear energy absorption coefficient, $\sigma$, as a function of energy is stored in the subroutine CALCUL. The table consists of two arrays: the energies, which are the independent variables, are contained in the array, $E$; the array, SIGMA, contains the linear energy absorption coefficients and is in one-to-one correspondence with the energy array. There are 22 entries in each array, and the largest and smallest entries in the energy array are $5.0 \mathrm{MeV}$ and $0.01 \mathrm{MeV}$, respectively. From this table the code uses the subroutine LAGRAN (ref. 7) to generate a second table, TABLE, 
(currently, containing 1001 entries) by means of Lagrangian log-log interpolation. Then for each $E_{\gamma i n}$, the code chooses the appropriate value for $\sigma$ from the generated table by the following method:

$$
\sigma=\operatorname{TABLE}(K)
$$

where

$$
K=\ln \left(E_{Y i n} / 0.01\right)+1.49
$$

DELX is the spacing of the generated table, TABLE. If $E_{\gamma \text { in }}<0.01 \mathrm{MeV}$, the code chooses the value of $\sigma$ for $E_{\gamma i n}=0.01 \mathrm{MeV}$. If $E_{\text {yin }}>5.0 \mathrm{MeV}$, EXREM III chooses the value of $\sigma$ for $E_{\gamma \text { in }}=5.0 \mathrm{MeV}$.

The backscatter correction, Bs, (see ref. 3 ) is equal to 1.14 (dimensionless). The density of air is stored as $1.2 \times 10^{-3} \mathrm{~g} / \mathrm{cm}^{3}$ $\left(20^{\circ} \mathrm{C}\right.$ and $76 \mathrm{~cm} \mathrm{Hg}$ pressure, see ref. 8$)$. 


\subsection{Description of Subroutines}

\subsubsection{Overview}

The MAIN PROGRAM controls the other subroutines.

AINPUT reads the input parameters.

PRINT prints the basic input parameters.

CALCUL calculates sum of the beta, positron, and electron dose factors and the gamma-ray dose-rate factors defined in Section 2.2 and performs other basic calculations.

LAGRAN and G3R3G3 are the Lagrangian interpolation subroutines used by CALCUL to approximate $\sigma$ in Eq. (8). (See ref. 7.)

ENOFX is the subroutine used by CALCUL to approximate the E-function in Eq. (8). (See ref. 9.)

TOTCON estimates the total concentration from $t_{1}$ to $t_{2}$ [i.e., the integral in Eq. (2)].

CONRAT estimates the concentration at time $t\left[i . e ., c_{i p \ell}(t)\right.$ in Eq. (1)].

CHAIN estimates $C_{i p \ell}(t)$ defined by Eq. (15). CHAIN is used by both TOTCON and CONRAT.

OUTPUT performs the final calculations indicated by Eqs. (1) and (2) and prints the headings for each case.

OUTARA prints the answer array for each case.

ORDER arranges the doses from radionuclides in descending order before they are printed by OUTARA. 
FMTGEN generates the format for the output of each line in the answer array.

CORE determines the size of the storage area in memory for use by the large variably dimensioned arrays.

BLOCK DATA initializes parameters and limits, some of which are used as variable dimensions.

SPECTRA locates and retrieves from scratch disk storage the energies and intensities of the selected nuclides.

The FREEFORM ${ }^{10}$ subroutines allow the reading of unformatted (free form) input.

\subsubsection{Variable Dimensioning}

The large data arrays are stored in blank COMMON. The maximum space is governed by the subroutine CORE. The following is an example of CORE which reserves 2000 words (8K bytes) of storage.

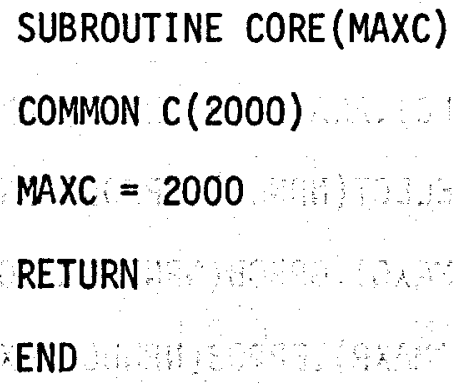

The value of MAXC is returned to the main routine for comparison wi th NEED, the computed requirement based on input and BLOCK DATA. If NEED > MAXC, the problem is terminated. 
The BLOCK DATA routine sets limits. The routine provided with the reference version of EXREM III is as follows:

BLOCK DATA

COMMON/MAX/MAXDET, MAXDR, MAXHTS, MAXNUC, MAXTD

COMMON/OUTI/TI(50), T2(50), TIME(50), TITLE(20), IDET, LIST, MAXB,

IMAXG, NDOSER, NTDOSE, MAXP, MAXE

COMMON/XCHAIN/MAXINC, MAXNUM, NCHAIN, MAXCHN

COMMON/OUT2/ILOC, MAXLIN, IYEAR

COMMON/PARM/HEIGHT (3) , IAIR, ISUR, IWATER, NDET, NHTS, NLOC, NRNUC, MAXLOC

REAL*8 RADNUC

DATA MAXDET/25/,MAXDR/50/,MAXHTS/3/,

1 MAXNUC $/ 250 /$, MAXTD $/ 50 /$, MAXB $/ 15 /$, MAXG/30/,MAXP/3/, MAXE/30/,

2MAXINC/10/,MAXLIN/55/,MAXLOC/2/,MAXNUM/500/

END

Space is reserved in $C$ as follows:

RADNUC (2・NRNUC), ANAME1 (2-NRNUC), ANAME2(2・NRNUC), ANAME3(2・NRNUC), NBETA(NRNUC), NGAMMA(NRNUC), NELECT (NRNUC), BPROB (NRNUC*MAXB), EO(NRNUC*MAXB), GENERY (NRNUC*MAXG), GPROB (NRNUC*MAXG),

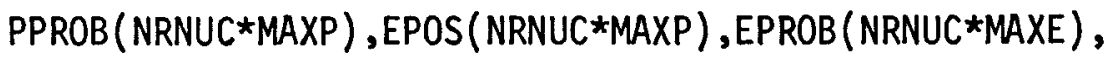
EELECT(NRNUC*MAXE), Y (NRNUC*NTAU), IATOM(NRNUC), F(NCHAIN, MAXINC), NUMNUC (NCHAIN), IDATA(2-NRNUC), GA(NRNUC*NLOC*NTAU), GS(NRNUC*NLOC*NTAU), GW(NRNUC*NLOC*NTAU), $\operatorname{RDECAY}(N R N U C), \operatorname{GDDOSE}(2 \cdot \operatorname{NRNUC} * N H T S), \operatorname{SUBDOSE}(2 * 2 \star N R N U C)$, $\operatorname{DOSE}(2 \cdot N R N U C), C A(N R N U C * N L O C), C S(N R N U C * N L O C), C W(N R N U C * N L O C)$, 
IFLAG(NRNUC*NLOC), IFILE(NRNUC), BENERY (NRNUC*MAXB), PENERY (NRNUC*MAXP), VALUEI (NRNUC), VALUE2 (NRNUC), VALUE3 (NRNUC), ID1 (NRNUC), ID2 (NRNUC), ID2 (NRNUC), LABEL1 (NRNUC), LABEL2(NRNUC), LABEL 3(NRNUC).

With the BLOCK DATA as given, NEED can be calculated from:

NEED $=$ NRNUC $(180+3 \cdot N T A U(N L O C+1)+4 \cdot N L O C+2 \cdot N H T S)+21 \cdot$ NCHAIN

In general:

NEED $=$ NRNUC $(3 \cdot M A X B+2 \cdot M A X G+3 \cdot M A X P+2 \cdot M A X E+3 \cdot N T A U(N L O C+1)$

$+4 \cdot N L O C+2 \cdot N H T S)+N C H A I N(2 \cdot M A X I N C+1)$

In the subroutine CORE, $C$ must be dimensioned $\geq$ NEED.

Several examples:

171 nuclides, 137 pathways, NEED $\approx 40000$

6 nuclides, 5 pathways, NEED $\approx 1500$

\subsection{Definition of Program Variables}

The FORTRAN variables used in EXREM III are defined in this section. These variables, listed in alphabetical order, are divided into three groups: the input variables, the more important internal variables, and the output variables. The subscript I denotes the Ith radionuclide, the subscript $\mathrm{J}$ denotes electron, ( $\mathrm{J}=1$ for beta, positron, or conversion/ Auger electron) or photon ( $\mathrm{l}=2$ for gamma ray or $x$-ray) radiation, the subscript $K$ denotes the $K$ th release, the subscript $L$ denotes the $L$ th location, the subscript $N$ denotes the Nth beta particle: or photon, the 
subscript NP denotes the NPth pathway, and the subscript IP denotes the IPth radionuclide in a pathway. Variables marked $A$ are obtained from the data base; variables marked $B$ are problem input. Variables marked by * determine dimensioning (see Section 3.3.2 Variable Dimensioning).

Input Variables

B ALCF:

Location correction factor $\left(\mathrm{cm}^{-3}\right), \mathrm{g}_{\text {ailk }}$, defined in Section 2.3. (To be used if the location correction factor is constant.)

A $\quad B P R O B(I, N): \quad$ Abundance (dimensionless), $f_{B i n}$, defined in Section 2.2.

B $\operatorname{CLOUDT}(K): \quad$ Time $(h r), t_{c}$, required for the cloud from the kth detonation to pass the area of concern (defined in Section 2.3.).

A $\operatorname{EELECT}(I, N)$ : Energy (MeV) of conversion/Auger electron, see Section 2.2.2.

A $\quad E O(I, N): \quad$ Maximum energy $(M e V), E_{B i n}$, defined in Section 2.2.

A $\operatorname{EPOS}(\mathrm{I}, \mathrm{N}): \quad$ Energy (MeV) of positrons, see Section 2.2.2.

A $\operatorname{EPROB}(I, N): \ldots$ Abundance (dimensionless), $f_{\text {ein }}$, see Section 2.2.2.

A $F(N P, I P): \quad$ The fraction of the IPth radionuclide which decays to the IP+1 st nuclide in the NPth pathway. B $\quad G A(I, L, K): \quad$ Location correction factor $\left(\mathrm{cm}^{-3}\right), g_{a i \ell k}$, defined in Section 2.3.

A $\operatorname{GENERY}(I, N): \quad$ Energy $(M e V), E_{\gamma i n}$, defined in Section 2.2. 
A $\operatorname{GPROB}(I, N): \quad$ Abundance (dimensionless), $f_{\gamma i n}$, defined in Section 2.2.

B $\quad G S(I, L, K)$ Location correction factor $\left(\mathrm{cm}^{-2}\right), g_{\text {silk }}$, defined in Section 2.3.:

B GW( $I, L, K): \quad$ Location correction factor $\left(\mathrm{cm}^{-3}\right), g_{\text {wi ll }}$, defined in Section 2.3.

B HEIGHT(IH): The IHth distance $(\mathrm{cm}), x$, of an individual from a contaminated surface (see Section 2.2).

B IAIR: Flag for submersion in air. If IAIR $\neq 0$, the dose rates and total doses for submersion in air are calculated. If IAIR $=0$, the calculations are omitted.

A $\operatorname{IATOM}(\mathrm{I})$ : Atomic number, $z_{i}$, defined in Section 3.2 .

A ICHAIN(NP, IP): The index, NONUC(I), for the IPth radionuclide in the NPth pathway.

B IDET: Releàse reference number. All time parameters entered as input should be measured relative to the time of this release ( $t=0$ at release IDET). B ISUR: flag for exposure to a surface, If ISUR $\neq 0$, the dose rates and total doses for exposure to a contaminated surface are calculated. If ISUR=0, the calculations are omitted. 
B IWATER:

Flag for submersion in water. If IWATER $\neq 0$, the dose rates and total doses for submersion in water are calculated. If IWATER=0, the calculations are omitted.

B LIST: Output flag. LIST=0 deletes the listing of the input data. LIST $=1$ lists the input data and solves the problem. LIST=2 lists the input data and stops without solving the problem.

A NBETA(I): Number of beta particles, $N_{B i}$, defined in Section $2.2[\mathrm{NBETA}(\mathrm{I}) \leq \mathrm{MAXB}]$.

$B^{*}$ NCHAIN :

Maximum number of nuclide pathways. The actual number ( $\leq$ NCHAIN) depends on data base.

$B * \quad \operatorname{NDET}(N T A U)$ :

Number of releases (NDET $\leq$ MAXDET).

B NDOSER:

Number of times, $t$, for the dose rate calculation $($ NDOSER $\leq$ MAXDR)

A NELECT(I): Number of electrons, $N_{e j}$, see Section 2.2.2 $[\operatorname{NELECT}(\mathrm{I}) \leq \mathrm{MAXE}]$

A $\quad \operatorname{NGAMMA}(\mathrm{I})$ : Number of gamma or $x$-ray photons, $\mathrm{N}_{\gamma j}$, defined in Section 2.2 [NGAMMA(I) $\leq$ MAXG].

B* NHTS : Number of distances from a contaminated surface for which the dose is to be calculated (NHTS $\leq$ MAXHTS).

$B * \quad$ NLOC: $\quad$ Number of locations (NLOC $\leq$ MAXLOC). 
A NONUC(I):

An index used to identify the Ith radionuclide [NONUC(I) $\leq$ MAXNUM].

A NPOS(I):

Number of positrons, $\mathrm{N}_{\mathrm{pi}}$; see Section 2.2.2.

$B^{*} \quad$ NRNUC:

Number of radionuclides (NRNUC $\leq$ MAXNUC).

B NTAU(NDET):

Number of releases (NTAU $\leq$ MAXDET).

B NTDOSE:

Number of time intervals, $\left[t_{1}, t_{2}\right]$, for the

total dose calculation (NTDOSE $\leq$ MAXTD).

A NUMNUC(NC):

Number of radionuclides in the NCth pathway $[$ NUMNUC (NC) $\leq$ MAXINC)].

A PPROB(I)

Abundance (dimensionless), $f_{\text {pin }}$, see Section 2.2.2.

B RADNUC(I):

The name of the Ith radionuclide (REAL*8).

A $\operatorname{RDECAY}(\mathrm{I})$ :

The radiological decay constant, $\left(\mathrm{hr}^{-1}\right), \lambda_{i}$, defined in Section 2.3.

B SLCF:

Location correction factor $\left(\mathrm{cm}^{-2}\right), g_{\text {silk }}$, defined in Section 2.3. (To be used if the location correction factor is constant.)

B $\operatorname{TAU}(K)$ :

Time of the kth environmental release $(h r)$, $t_{k}$, defined in Section 2.4 .

B TIME(II): Time for dose-rate calculation $(\mathrm{hr}), \mathrm{t}$, for the IIth case.

B TIMEUNIT: Alphanumeric switch to set time unit of dose rate. If TIMEUNIT $=\gamma$ or YEAR, the dose is in units of millirem/yr. If TIMEUNIT is anything else, the unit is millirem/hr.

B TITLE: An array containing the title of the problem. 
B TI(II):

B T2(II):

B WLCF:

B. $\quad Y(I, K)$ :

Internal Variables

$A(I H):$

$\operatorname{BENERY}(I, N)$ :

BS :

C:

$C A(I, L):$

$\operatorname{CON}(J, I T):$
Lower limit of integration $(h r), t_{j}$, for the calculation of the total dose for the IIth case.

Upper limit of integration $(h r), t_{2}$, for the calculation of the total dose for the IIth case.

Location correction factor $\left(\mathrm{cm}^{-3}\right), g_{\text {wilk}}$, defined in Section 2.3. (To be used if the location correction factor is constant.)

Yield released $(\mu \mathrm{C} i), Y_{i k}$, defined in Section

\section{3.}

HEIGHT $(\mathrm{IH}) * 1.2 \mathrm{E}-3,\left(\mathrm{~g} / \mathrm{cm}^{2}\right)$.

Average energy (MeV), $\bar{E}_{B i n}$, defined in Section 2.2

Backscatter correction, Bs, defined in Section

2.2 .

Location of variably dimensioned data (blank COMMON).

Either $C_{i a l}(t)$ defined in Sect. 2.3 or $I_{i a l}\left(t_{1}, t_{2}\right)$ defined in Section 2.4.

An array containing the coefficients

$\frac{25.6}{24.0}, \frac{51.2}{24.0}, \frac{29.2}{(24.0)(1.2 E-3)}, \frac{29.2}{(24.0)(1.2 E-3)} \cdot$

( $I T=1$ for submersion in water; IT=2 for

submersion in air.) 
$\operatorname{CS}(I, L): \quad$ Either $C_{i S \ell}(t)$ defined in Section 2.3 or $I_{\text {is } \ell}\left(t_{1}, t_{2}\right)$ defined in Section 2.4 .

$\operatorname{CW}(I, L): \quad \quad \quad \quad \quad \quad \quad$ ither $C_{i W \ell}(t)$ defined in Section 2.3 or $I_{\text {iwe }}\left(t_{1}, t_{2}\right)$ defined in Section 2.4 .

El(1): Contains the value of $E_{1}(\sigma \cdot x)$. $\operatorname{GDDOSE}(I, J, I H):$ Dose rate factor, $D_{i j s}$, at the IHth height (defined in Section 2.2).

* MAXB: Maximum number of beta particles (MAXB=15).

MAXC: Size (in words) of C (subroutine CORE).

MAXCHN: Maximum number of nuclide pathways equals NCHAIN.

MAXDET : Maximum number of releases (MAXDET=25).

* MAXE:

Maximum number of conversion/Auger electrons $($ MAXE $=30)$.

MAXDR:

Maximum number of dose rate calculations for a problem $($ MAXDR $=50)$.

* MAXG:

Maximum number of photons (MAXG $=30$ ).

MAXHTS:

Maximum number of heights above a contaminated surface (MAXHTS $=3$ ).

* MAXINC:

Maximum number of radionuclides in a pathway $($ MAXINC=10).

MAXLOC:

Maximum number of locations (MAXLOC=2).

MAXLIN:

Maximum number of lines on a page of output (MAXLIN=55).

MAXNUC:

Maximum number of radionuclides (MAXNUC=200).

MAXNUM:

Maximum radionuclide index (MAXNUM=500). 
* MAXP: Maximum number of positrons (MAXP=3).

MAXTD: Maximum number of total dose calculations for a problem (MAXTD=50).

NEED: Maximum number of 4-byte: locations (words) needed by variably dimensioned variables. Calculated in main routine based on input and BLOCK DATA routine.

$\operatorname{PENERY}(I, N):$

$\operatorname{SUBDOS}(I, J, M):$

Output Variables

$\operatorname{DOSE}(I, J):$

$D_{i p j \ell}(t)$ (millirem/hr or millirem/yr) defined in Eq. (1) or $T D_{i p j l}\left(t_{1}, t_{2}\right)$ defined in Eq. (2). The electron dose rate includes beta rays, positrons, and conversion and Auger electrons. L: The Lth location.

TOTAL: An array containing the sum of the dose rates or total doses for 217 radionuclides.'

The output variables IDET, NONUC(I), RADNUC(I), HEIGHT(IH), TIME(II), TITLE, TI(II), and T2(II) were defined above. 


\subsection{DESCRIPTION OF INPUT}

A description of the card input for EXREM III is presented in this section. The entire deck for a problem is divided into eight groups which are listed below. Except for the TITLE card and Group 2, columns 73 through 80 are reserved for identification to aid the user in the preparation and handling of the data. Examples are given to suggest identification for each card.

\subsubsection{Input Categories}

A. Data Base (formatted)

1. Group 1
a. Data base unit number
b. NUCLID cards

2. Group 2
a. B cards
b. $P$ cards
c. E cards
d. G cards

3. Group 3
a. PAT card?
b. FRA card $\}$ for each pathway

B. Problem Input (all free field except title card)

4. Group 4 (formatted)
a. TITLE card 
5. Group 5 (free field)
a. LIMIT card
b. HEIGHT card
c. DETON card

6. Group 6

RADNUC cards

7. Group 7

PROD cards

8. Group 8
a. WLOC cards
b. ALOC cards
c. SLOC cards

9. Group 9

CLOUD card

10. Group 10
a. DOSRAT card
b. TOTDOS card

\subsubsection{Description of Each Group}

Each card is described by listing the variables in the order in which they are to be entered, by giving the FORTRAN format used to read the card, including identification to be used. The input variables were defined in Section 3.4 . 
A. Data Base (Formatted)

1. Group 1

a. Data Base Unit Number

Variable Read: IM

Format (I3)

This is the unit number for reading the data base. It may be the normal input unit or may be another unit.

b. NUCLID $_{i}$ cards for $i=1,2, \ldots$, NRNUC.

Variables Read: NONUC(I), IATOM(I), RADNUC(I), $\operatorname{RDECAY}(I), \operatorname{NBETA}(I), \operatorname{NGAMMA}(I), \operatorname{NPOS}(I), \operatorname{NELECT}(I)$, for $I=i$.

Format: $(2 \mathrm{I} 3, \mathrm{~A} 8, \mathrm{IX}, \mathrm{E} 10.0,4 \mathrm{I} 5)$.

Identification: Reference number (source of data) in column 73. See Sppendix B.

Identification: Enter the word NUCLID in columns 75-80.

The radionuclide names (RADNUC) should be left-adjusted

in columns 7-13. In order for the radionuclide SR-90

to be treated as described in Section 2.2, the index, NONUC(I), must equal 42.

2. Group 2

a. $B_{j}$ cards for $i=1,2, \ldots$.

Variables Read: (EO (I,IP), $B P R O B(I, I P)$ ) for $I P=1$, $2, \ldots . ., \operatorname{NBETA}(I)$ and for $I=i, \operatorname{NONUC}(I)$.

Format: $(12 E 6.0,5 X .,=13)$.

Identification: Enter $B$ in column 73 and the value of NONUC(I) in columns 78-80. The values of NONUC(I) are required by EXREM III to find the data. 
There can be six sets of energies and abundances per card. For each radionuclide $i$, the code continues to read B cards until all these sets have been read. The data are terminated by a blank card (may have zeros). If $\operatorname{NBETA}(I)=0$ for a particular $I$, then the B card corresponding to that radionuclide is omitted. The data for the radionuclides should appear in the same sequence as the radionuclides appeared in Group 1.

b. $P_{j}$ cards for $i=1,2, \ldots$

Variables Read: $[E P O S(I, I P), P P R O B(I, I P)]$ for $I P=1,2$, ..., NPOS(I) and for $I=i, \operatorname{NONUC(I).~}$

Format: $(12 \mathrm{E} 6.0,5 \mathrm{X}, \mathrm{I3})$.

Identification: Enter $P$ in column 73 and the value of NONUC(I) in columns $78-80$.

There can be six sets of energies and abundances per card. For each radionuclide $i$, the code continues to read $P$ cards until all these sets have been read. The data are terminated by a blank card (may have zeros). If $\operatorname{NPOS}(I)=0$ for a particular nuclide, then the $\mathrm{P}$ card corresponding to that radionuclide is omitted. The data for the radionuclides should appear in the same sequence as the radionuclides appeared in Group 1.

c. $E_{j}$ cards for $i=1,2, \ldots$ Variables Read: [EELECT(I,IP), EPROB (I,IP)] for $I P=1$, $2, \ldots, \operatorname{NELECT}(I)$ and for $I=i, \operatorname{NONUC}(I)$. 
Format: $(12 \mathrm{E} 6.0,5 \mathrm{X}, \mathrm{I} 3)$.

Identification: Enter $E$ in column 73 and the value of NONUC(I) in columns $78-80$.

There can be six sets of energies and abundances per card. For each radionuclide $i$, the code continues to read $E$ cards until all these sets have been read. The data are terminated by a blank card (may have zeros). If $\operatorname{NELECT(I)=0~for~a~particular~nuclide,~}$ then the $P$ card corresponding to that radionuclide is omitted. The data for the radionuclides should appear in the same sequence as the radionuclides appeared in Group 1.

d. $G_{i}$ cards for $i=1,2$, ... Variables Read: (GENERY (I,IP), GPROB (I,IP)) for IP=1, 2,... NGAMMA(I) and for $I=i, \operatorname{NONUC}(I)$.

Format: $(12 E 6.0,5 X, I 3)$.

Identification: Enter $G$ in column 73 and the value of NONUC(I) in columns $78-80$.

There can be six sets of energies and abundances per card. For each radionuclide 1 , the code continues to read $G$ cards until all these sets have been read. The data are terminated by a blank card (may have zeros). If NGAMMA(I) $=0$ for a particular nuclide, then the $G$ card corresponding to that radionuclide is omitted. The data for the radionuclides should appear 
in the same sequence as the radionuclides appeared in Group 1.

\section{Group 3}

This group consists of a PAT card and a FRA card for each nuclide pathway. The group is repeated for each pathway in a nuclide chain and then for each nuclide chain.

a. PAT card for the NPth nuclide pathway.

Variables Read: NUMNUC(NP), ICHAIN(NP,IP) for $I P=1,2, \ldots, \ldots$ NUMNUC (NP).

Format: (1415).

Identification: Enter the number of the pathway in column 71 , the total number of pathways for the chain in column 72 , the mass chain index in columns $74-76$, and the word PAT in columns $78-80$.

NOTE: To indicate additional contributions to a nuclide which appeared in a previous pathway, add 500 to the nuclide index. (See Section 2.3.)

b. FRA card for the NPth nuclide pathway. Variables Read: $F(N P, I P)$ for $I P=1,2, \ldots .$, NUMNUC(NP).

Format: $(5 X, 13 F 5.0)$.

Identification: Enter the number of the pathway in column 71, the total number of pathways for the chain 
in column 72 , the mass chain index in columns $74-76$, and the word FRA in columns $78-80$.

The data are terminated by a blank card (may be zeros).

B. Problem Input

4. Group 4 (Formatted)

TITLE card.

Variables Read: $\operatorname{TITLE}(\mathrm{J})$ for $\mathrm{J}=1,2, \ldots, 20$.

Format: (20A4)

This card contains the title for the problem which

can be from 1 to 80 alphanumeric characters and which

should be centered on the card.

5. Group 5 (Unformatted, free field) *

a. LIMIT card.

Variables Read: NRNUC, NCHAIN, NTAU, NLOC, NHTS, IDET, IWATER, IAIR, ISUR, LIST, NDOSER, NTDOSE, TIMEUNIT

Form: 12 integers, alphanumeric character(s)

NOTE: If CLOUDT $(K)=$ CLOUD for each release, then enter

NTAU as a negative number so that $\mid$ NTAU $=$ number of

releases. Then Group 9 will be omitted. See Par. 6

of Section 3.5.2.

NOTE: If the location correction factor is constant for each mode of exposure, then enter NLOC as a negative number

\footnotetext{
* The unformatted, free field data variables must be separated by at least one blank. As many data "islands" may appear on a card as desired. For convenience, however, the data description will be described here as "cards".
} 
so that $|N L O C|=$ number of locations and for Group 8, use the cards described in Par. 4b of Section 3.5.2. Otherwise, let NLOC = number of locations and for Group 8, use the cards described in Par. 4a of Section 3.5.2. NOTE: TIMEUNIT should be YEAR or $Y$ to make the dose rate units mrem/yr. If TIMEUNIT is HR (or something else), the dose rate is in units of $\mathrm{mrem} / \mathrm{hr}$.

b. HEIGHT card.

Variables Read: HEIGHT(IH) for IH $=1,2, \ldots$ NHTS.

Form: real

NOTE: If ISUR $=0$, then the HEIGHT card is omitted.

c. RELEASE TIME card.

Variables Read: $\operatorname{TAU}(K)$ for $K=1,2, \ldots$.. NTAU.

Form: real

The code continues to read cards until all NTAU release times have been read.

6. Group 6

RADNUC $_{j}$ cards for $i=1,2, \ldots . ., N R N U C$.

Variables Read: RADNUC(I) for $I=1,2, \ldots .$, NRNUC.

Form: Alphanumeric

Example: ZR95M

This input specifies the particular nuclides to be treated in the problem. It is necessary that data for these nuclides be present in the data base. 


\section{Group 7}

$\mathrm{PROD}_{i}$ cards for $i=1,2, \ldots, \ldots$ NRNUC.

Variables Read: $Y(I, K)$ for $K=1,2, \ldots$, NTAU and for $\mathrm{I}=\mathbf{i}$.

Form: real.

For each radionuclide $i$, the code continues to read PROD cards until all NTAU release quantities have been read. The data for the radionuclides must appear in the same sequence as the radionuclides appeared in Group 6. If all releases are the same for nuclide I and subsequent nuclides, this can be specified by giving $Y(I+1,1)<0$ as the final data value. For example, Let $N T A U=2, N R N U C=100$ and all $Y(I, 1)=1$, and $Y(I, 2)=2$. The data can be entered as: $1,2,-1$.

8. Group 8

This group consists of sets of WLOC, ALOC, and SLOC cards containing the location correction factors for submersion in water, submersion in air, and exposure to a surface, respectively. The entire group is repeated for each location $\ell$, where $\ell=1,2, \ldots ., N L O C$.

a. When NLOC $>0$, Group 8 has the following form:

(1) $W_{L O C}{ }_{i \ell}$ cards for $i=7,2, \ldots$, NRNUC.

Variables Read: $G W(I, L, K)$ for $K=1,2, \ldots$ NTAU and for $I=i$ and $L=\ell$.

Form: real. 
For each radionuclide $i$, the code continues to read WLOC cards until all NDET factors have been read. The data for the radionuclides must appear in the same sequence as the radionuclides appeared in Group 6 . NOTE: If IWATER $=0$, the WLOC cards are omitted. (2) ALOC $_{i \ell}$ cards for $i=7,2, \ldots$ NRNUC.

Variables Read: $G A(I, L, K)$ for $K=7,2, \ldots ., N T A U$ and for $I=i$ and $L=\ell$.

Form: real.

For each radionuclide $i$, the code continues to read ALOC cards until all NTAU factors have been read. The data for the radionuclides must appear in the same sequence as the radionuclides appeared in Group 6 . NOTE: If IAIR $=0$, the ALOC cards are omitted.

(3) $\mathrm{SLOC}_{i \ell}$ cards for $i=1,2, \ldots$.. NRNUC.

Variables Read: $G S(I, L, K)$ for $K=1,2, \ldots, N T A U$ for $I=i$ and $L=l$.

Form: real.

For each radionuclide $i$, the code continues to read SLOC cards until all NDET factors have been read. The data for the radionuclides must appear in the same sequence as the radionuclides appeared in Group 6 . NOTE: If ISUR=0, the SLOC cards are omitted. 
b. When NLOC $<0$, Group 8 has the following form:

(1) WLOC card.

Variable Read: WLCF for $L=\ell$.

Format: real.

NOTE: If IWATER $=0$, the WLOC card is omitted.

(2) ALOC card.

Variable Read: ALCF for $L=\ell$.

Format: real.

NOTE: If IAIR $=0$, the ALOC card is omitted.

(3) SLOC card.

Variables Read: SLCF for $L=\ell$ :

Format: real.

NOTE: If ISUR $=0$, the SLOC card is omitted.

9. Group 9

CLOUD card.

Variables Read: $\operatorname{CLOUDT}(K)$ for $K=1,2, \ldots$ NTAU

Format: real.

The code continues to read CLOUD cards until all

NTAU of the CLOUDT times have been read.

NOTE: If NTAU < 0 , then Group 9 is omitted, and the code assumes that CLOUDT=CLOUD for each release (currently, CLOUD $=1.0$ hours).

NOTE: If IAIR=0 then Group 9 is omitted. 
10. Group 10

a. DOSRAT card.

Variables Read: $\operatorname{TIME}(\mathrm{J})$ for $\mathrm{J}=1,2, \ldots$, NDOSER.

Format: real.

The code continues to read DOSRAT cards until

all NDOSER of the entries have been read.

NOTE: If NDOSER $=0$, then these cards are omitted.

b. TOTDOS card.

Variables Read: $T 1(\mathrm{~J}), T 2(\mathrm{~J})$ for $\mathrm{J}=1,2, \ldots$

NTDOSE.

Format: real.

The code continues to read pairs of values until all NTDOSE of the integration limits, $T 1$ and T2, have been read.

NOTE: If NTDOSE $=0$, then these cards are omitted.

\subsubsection{Input Summary}

Data Base Input Summary

1. (a) Data Base Unit, IM

(b) NUCLID (Repeat for all nuclides)

NONUC (I), IATOM(I), RADNUC(I), RDECAY(I),

$\operatorname{NBETA}(I), N G A M M A(I), N P O S$ (I), NELECT(I)

Blank card

2. (a) Betas (Repeat for all nuclides)

(EO(I,IP), BPROB (I, IP), IP =1, NBETA(I)),

NONUC (I)
Format

$(213, A 8,1 X, E 10.0,415)$

$(12 E 6.0,5 X, I 3)$ 
Data Base Input Summary

Format

Blank Card

(b) Positrons (Repeat for all nuclides)

((EPOS(I,IP), PPROB (I,IP), IP $=1, N P O S(I))$,

NONUC (I)

$(12 E 6.0,5 X, 13)$

Blank card

(c) Electrons (Repeat for all nuclides)

( ( $\operatorname{EELECT}(I, I P), \operatorname{EPROB}(I, I P), I P=1$,

NELECT(I)),NONUC(I)

$(12 \mathrm{E} 6.0,5 \mathrm{X}, \mathrm{I} 3)$

Blank card

(d) Gamma or X-Rays (Repeat for all nuclides)

( $(\operatorname{GENERY}(I, I P), \operatorname{GPROB}(I, I P), I P=1, \operatorname{NGAMMA}(I))$,

NONUC(I)

$(12 \mathrm{E} 6,0,5 \mathrm{X}, \mathrm{I} 3)$

3. PAT, FRA

Repeat for $\begin{cases}\text { NUMNUC (NP), ICHAIN (NP, IP) } \\ \text { IP }=1, \text { NUMNUC (NP) } & (14 I 5) \\ F(N P, I P), I P=1, N U M N U C(N P) & (5 X, 13 F 5,0)\end{cases}$

Blank card

Problem Input Summary (Free Format)

4. Title $(80 \mathrm{col})$

5. LIMITS

(a) NRNUC, NCHAIN, NTAU, NLOC, NHTS, IDET, I WATER, IAIR, ISUR,

LIST, NDOSER, NTODOSE, TIMEUNIT

(b) (HEIGHT(IH), IH=1,NHTS)

(c) (TAU(K), $K=1, N T A U)$ 
6. Nuclides

(RADNUC(I), I=1, NRNUC)

7. Release Quantities (PROD)

$((Y(I, K), K=1, N T A U), I=1, N R N U C)$

8. Location Correction Factors

(a) If $\mathrm{NLOC}>0$

Read all factors $L=1, N L O C$

Repeat for $\begin{cases}((G W(I, L, K), K=I, N T A U), I=1, N R N U C) & (W L O C) \\ ((G A(I, L, K), K=1, N T A U), I=1, N R N U C) & \text { (ALOC) } \\ ((G S(I, L, K), K=1, N T A U), I=1, N R N U C) & \text { (SLOC) }\end{cases}$

(b) If NLOC $<0$ Factors constant for all times and nuClides.

Read all factors $L=1, N L O C$

WLCF,ALCF, SLCF (repeat for each location)

9. CLOUD Times

(CLOUDT (K), K=1, NTAU)

10. (a) DOSRAT Times

( $\operatorname{TIME}(\mathrm{J}), \mathrm{J}=1$, NDOSER)

(b) TOTDOS Times

$(\operatorname{TI}(\mathrm{J}), \mathrm{T} 2(\mathrm{~J}), \mathrm{J}=1, \mathrm{NTDOSE})$

\section{ACKNOWLEDGEMENTS}

The authors wish to acknowledge that the original code and much of this report was taken from the work of W. D. Turner, presently with Computer Sciences Division, Union Carbide Corporation, Nuclear Division, Oak Ridge, Tennessee. 
The assistance of C. F. Holoway, of the ORNL Information Center for Internal Exposure, in providing unpublished data, and F. C. Von derlage in computing otherwise unavailable emission spectra is also gratefully acknowledged. 


\section{REFERENCES}

1. W. Doyle Turner, The EXREM II Computer Code for Estimating External Doses to Populations from Construction of a Sea-Level Canal with Nuclear Exposure, CTC-8, Union Carbide Corp., Computing Technology Center (1969).

2. W. D. Turner, S. V. Kaye, and P. S. Rohwer, EXREM and INREM Computer Codes for Estimating Radiation Doses to Populations from Construction of a Sea-Level Canal with Nuclear Explosives, K-1752, Computing Technology Center and 0ak Ridge National Laboratory, Oak Ridge, Tennessee (September 1968).

3. K. E. Cowser, S. V. Kaye, P. S. Rohwer, W. S. Snyder, and E. G. Struxness, Dose-Estimation Studies Related to Proposed Construction of an Atlantic-Pacific Interoceanic Canal with Nuclear Explosives: Phase I, ORNL-4101, Oak Ridge National Laboratory, Oak Ridge, Tennessee (March 1967).

4. D. R. Vondy, Development of a General Method of Explicit Solution to the Nuclide Chain Equations for Digital Machine Calculations, ORNL-TM-361, Oak Ridge National Laboratory, Oak Ridge, Tennessee (October 1962).

5. Irving Kaplan, Nuclear Physics, Addison-Wesley Publishing Company, Inc., Reading, Massachusetts, 1955.

6. International Commission on Radiological Protection, Report of Committee II on Permissible Dose for Internal Radiation, ICRP Publ. 2, Pergamon Press, London (1959); Health Phys. 3 (June 1960). 
7. S. K. Penny, and M. B. Emmett, An IBM-7090 Subroutine Package for Lagrangian Interpolation, ORNL-3428, Oak Ridge National Laboratory, Oak Ridge, Tennessee (May 2, 1963).

8. Radiological Health Handbook, U.S. Dept. Health, Education, and Welfare, 1960.

9. S. K. Penny, D. K. Trubey, and M. B. Emmett, OGRE, A Monte Carlo System for Gamma-Ray Transport Studies, Including an Example (OGRE-PI) for Transmission Through Laminated Slabs, ORNL-3805, Oak Ridge National Laboratory, Oak Ridge, Tennessee (Apri1 1966).

10. R. C. Durfee, FORTRAN Free-Form Input, ORNL-CF-70-1-45, Oak Ridge National Laboratory Internal Memorandum (1970). 


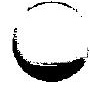




\section{APPENDIX A}

\section{SAMPLE PROBLEMS FOR EXREM III}

In this section, two examples are presented to illus trate the input format that is required to solve a problem using the code EXREM III.

\section{First Sample Problem for EXREM III}

Determine the dose-equivalent rates and the total dose equivalents from both beta and gamma radiation resulting from exposure from submersion in water, submersion in air and exposure $100 \mathrm{~cm}$ above a surface contaminated with the radionuclides $Z R-95, N B-95 M$, and NB-95. The radionuclides are the results of a single release. Calculate the dose rate one hour after the release and the total dose accumulated during the first hour after the release.

The following chain describes the decay process of the three radionuclides:

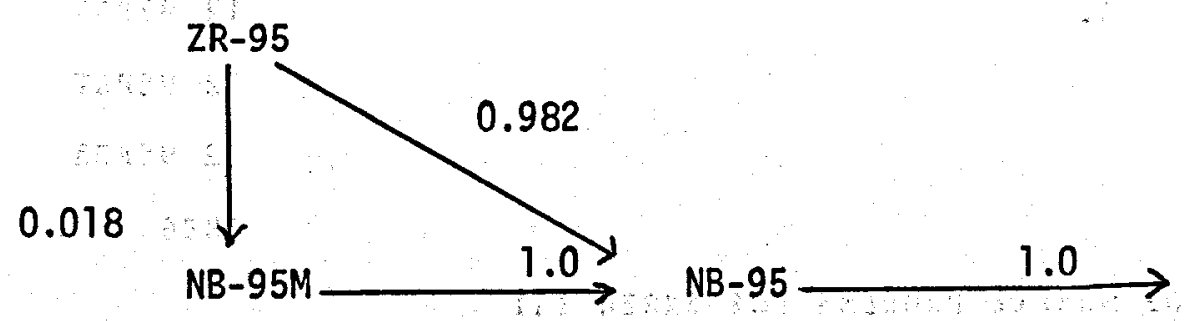

The format of the input cards containing the data necessary to describe the problem is given in Table 1, and the computer output for the problem is given in Table 2 . 
Table 1

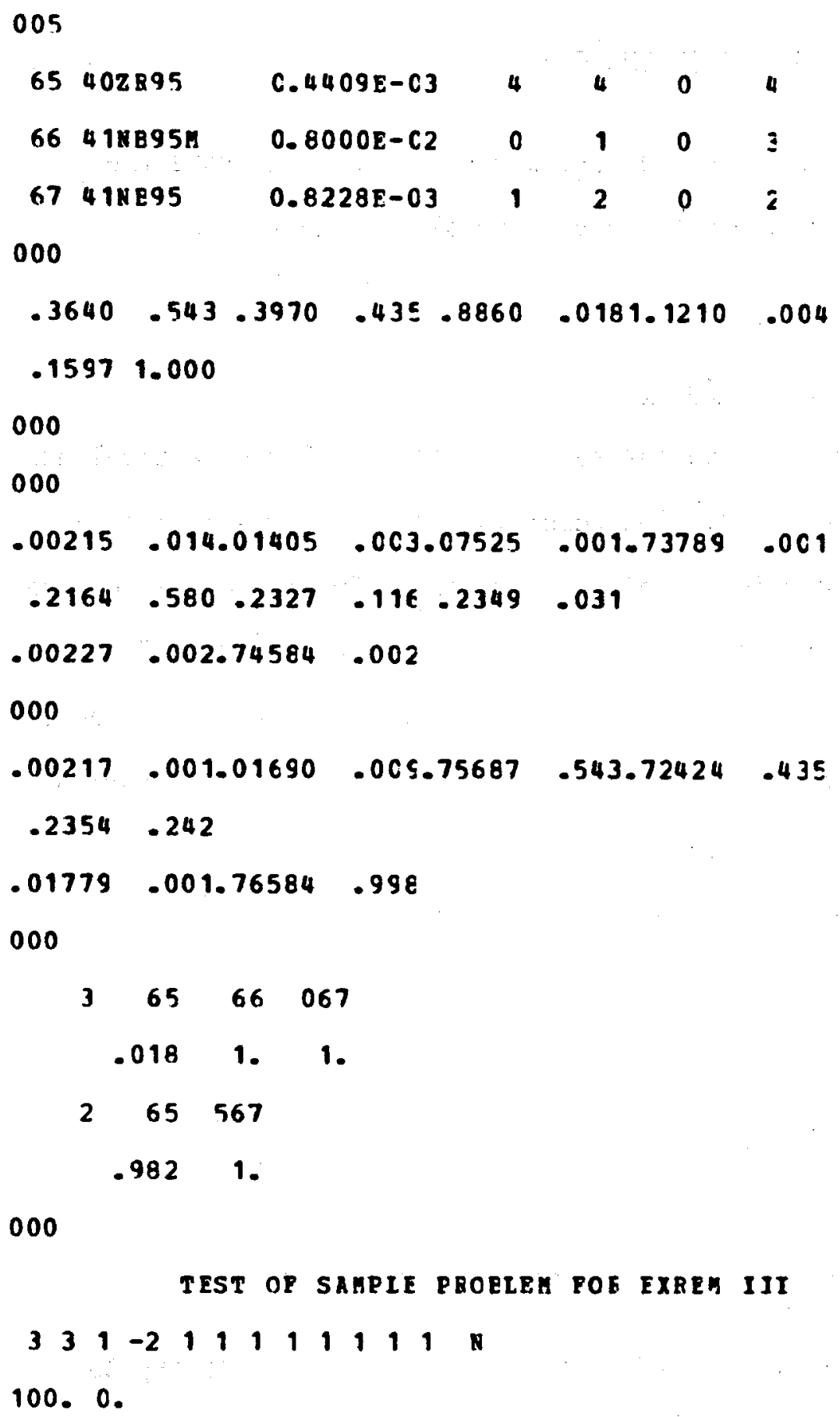


Table 2

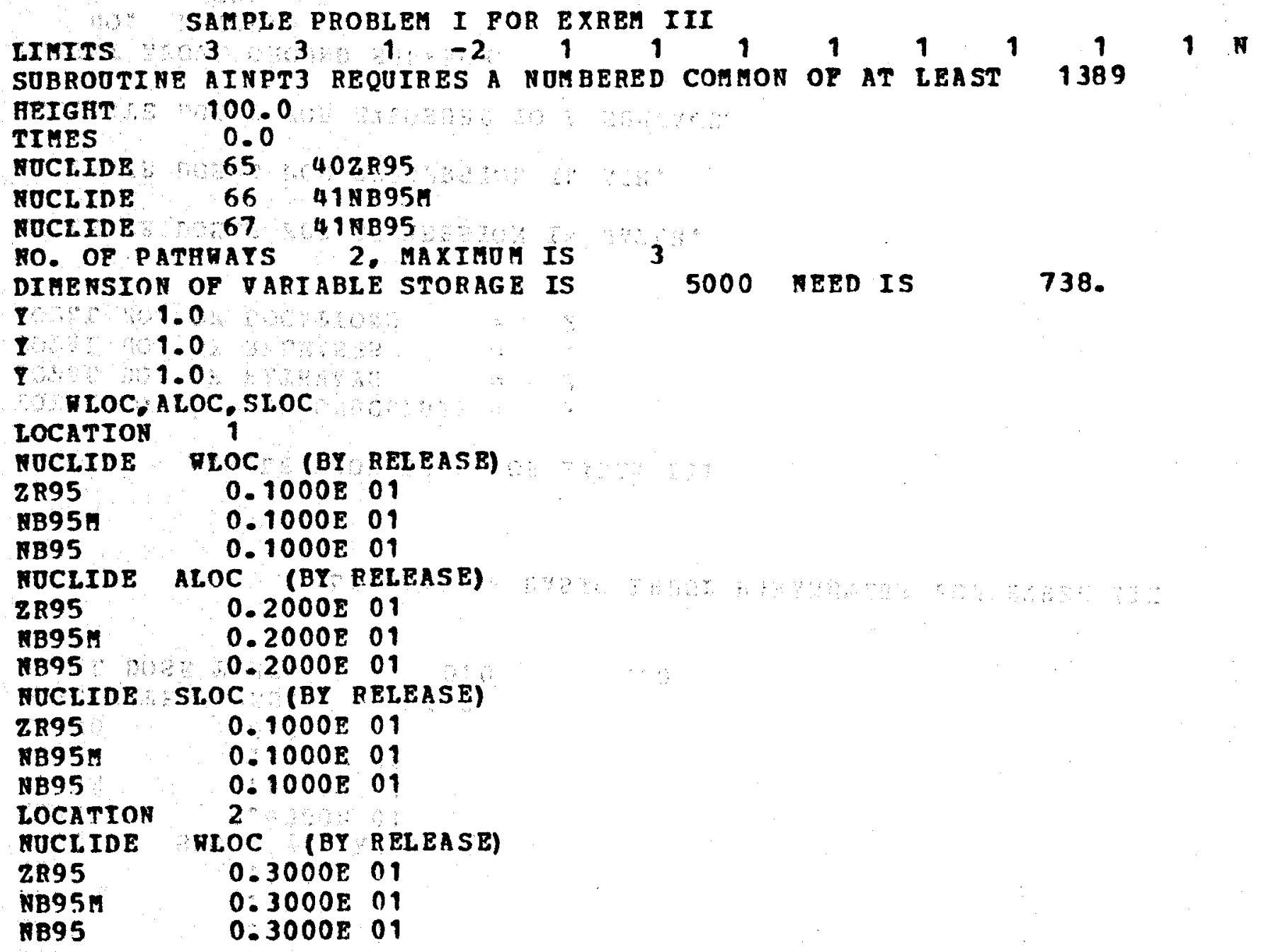




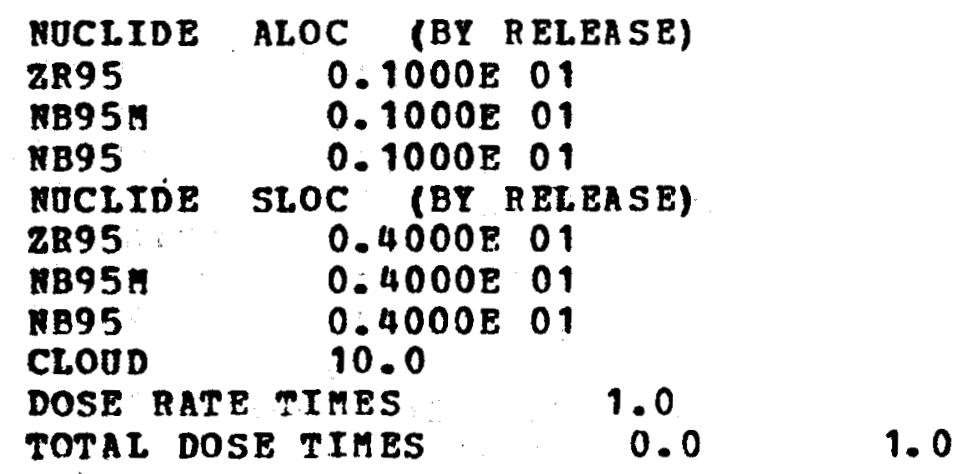

IISTING OP BASIC INPUT PARAMETERS FOF EXREE III

SAMPLE PROBLEM I POR EXREM IIT

TOTAI HO. OP RADIONUCLIDES $=3$

TOTAL NO. OP PATHNAYS $=2$

TOTAL 10. OP RELEASES $=1$

TOTAL HO. OP LOCATIOHS $=2$

ESTIHATE DOSES FOR SUBMERSTON IN DATER.

ESTIHATE DOSES POR SUBMERS ION IN AIR.

ESTIMATE DOSES FOR EXPOSURE TO A SURPACE.

HEIGRT ABOVE GROUND STRFACE.

NO. HEIGHT

(CH)

$1 \quad 100.000$ 
TTME OP EACH RELEASE.

NO. RELEASE

\section{CLOUD TIHE}

1

(HRS)

$$
0.0 \quad 10.0
$$

RADIONUCLIDE IDENTIFICATION.

INDEX ATOMIC NAME DECAT CONSTANT NO. BETANUMBER (1/HRS)

$\begin{array}{lccc}65 & 40 & \text { ZR95 } & 4.40900 \mathrm{E}-04 \\ 66 & 41 & \text { NBS } & 8.00000 \mathrm{E}-03 \\ 67 & 41 & \text { NB95 } & 8.22800 \mathrm{E}-04\end{array}$
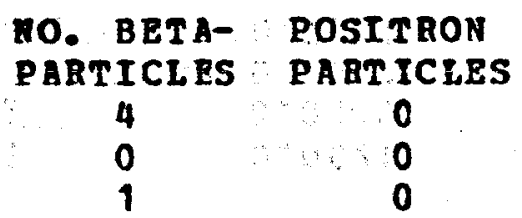

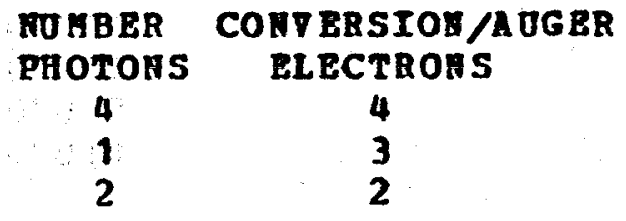

TIELD.

\begin{tabular}{|c|c|c|c|}
\hline NDEX & RADIONOCIIDE & $\begin{array}{c}\text { NUHBER OF } \\
\text { RELEASE }\end{array}$ & $\begin{array}{l}\text { NTITI } \\
\text { ROCORIE: }\end{array}$ \\
\hline $\begin{array}{l}65 \\
66\end{array}$ & & $\begin{array}{l}1 \\
1 \\
1\end{array}$ & $\begin{array}{ll}\text { E } & 00 \\
\text { OE } & 00 \\
\text { E } & 00\end{array}$ \\
\hline
\end{tabular}

LOCATION CORRECTION PACTOR.

POR ALL RADIONUCLIDES AND POR ALL RELEASES.

LOCATION SUBHERSION SUBHERSION RXPOSORE

IN AIR TO SURPACE

$1 \quad \begin{array}{lll}(1 / \mathrm{CC}) & (1 / \mathrm{CC}) & (1 / \mathrm{SQ} \mathrm{CM}) \\ 1.0000 \mathrm{E} 00 & 2.0000 \mathrm{E} 00 \quad 1.0000 \mathrm{E} 00\end{array}$

$2 \quad 3.0000 E$ OO 1.0000 E OO 4.0OOOE OO 
ENERGY AND INTENSITY POR BACH BETA PARTICLE. INDEX RADIONUCLIDE NO. MAXIHUH EHERGY (MEV)

$65 \quad 2 R 95$

$67 \quad$ NB95

$$
\begin{aligned}
& 0.3640 \\
& 0.3970 \\
& 0.8860
\end{aligned}
$$

1.1210

0.1597

1

ENERGY AND INTENSITY FOR EACH POSITRON.

INDEX RADIONOCLIDE NO. HAXTMOM BNERGY

(AEV)

ENERGY AND INTENSTTY FOR EACH ELFCTRON.

INDEX RADIONUCLIDE NO.

$$
\text { ENE RG Y }
$$

(AEV)

$65 \quad 2$ P95

1

2

4

66 NB95M

$67 \quad N B 95$

\subsection{9}

0.0140

0.0752

0.7379

0.2164

0.2327

0.2349

0.0023

0.7458
INTEHSITY (FRACT ION)
0.543
0.435
0.018
0.004
1.000

\section{IN TEMS ITY} (FRACTION)

IRTENSIT Y (FRACTION)
0.014
0.003
0.001
0.001
0.580
0.116
0.031
0.002
0.002

1
2 
ENERGY AND INTENSITY FOR EACH PHOTON. INDEX RADTONOCLIDE NO. ENERGY

(MEV)

652895

66 NB95

67 NB95

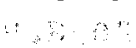

1

$\mathbf{1}$
0.0022

0.0169

0.7569

0.7242

0.2354

0.0178

0.7658
INTENSITY

(PRACTION)
0.001

0.009

0.543

0.435

0.242

0.001

0.998

RADIONOCLIDE PATHAAYS. PATREAT POSITION

\section{INDEX FRACTION}

$65 \quad 0.0180$

66.1 .0000

671.0000

2

$65 \quad 0.9820$ 
SAHPLE PROBLEM I POA EXREM III

LISTING OP RADIONOCLIDES POR SUBARSTON DOSE RATES IN COMTAMIMATED EATER

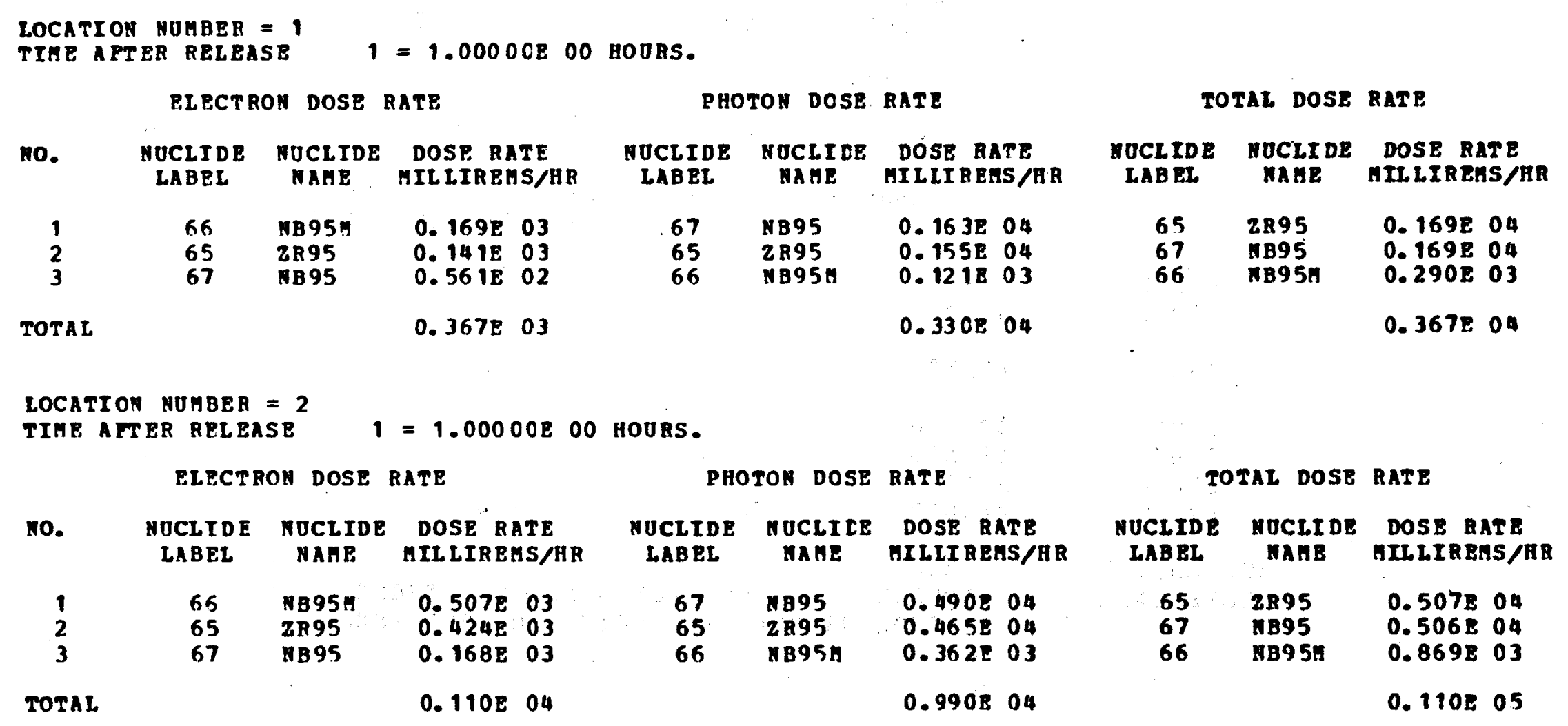




\section{SAMPLE PROBLEM I FOR EXREA III}

\section{LISTING OF RADIONUCIIDES FOR SUBAERSION DOSE RATES IA CORTAMTATED AIR}

LOCATION KUMBER $=1$

TIHE AFTER RELEASE

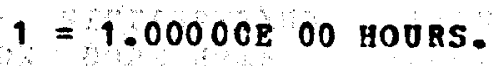

PLECTROA DOSE RATE

PHOTOH DOSP RATE

NO NUCLIDE
TABEL

DCLIDE DOSE RATE NARE HILLIREAS/HR

NUCLIDE
N UCLICE DOSE RATE 66 NB95m 65 2895

0. 321E 06 0.269 E 06

$0.1078,06$

\section{7}

65

\section{NB 95}

ZR95

NB95

$0.697 \mathrm{E} 06$
ILII BEAS/R R

0. 155E 07

0.147807

$0.115 \mathrm{E} 06$

$0.314 \mathrm{E} 07$
TOTAL DOSE RATE

$\begin{array}{ll}\text { NOCLIDE } & \text { NOCLIDE DOSE RATE } \\ \text { LABEL } & \text { MAHE HILIREAS/AR }\end{array}$

$\begin{array}{ll}65 & \text { ZR95 } \\ 67 & \text { NB95 } \\ 66 & \text { NB95 }\end{array}$

0.174807

$0.166 E 07$

$0.436 \mathrm{E} 06$

$0.383 E 07$

LOCATION NOHBER $=2$

TIRE AFTER RELEASE

$1=1.00000$ E 00 HOORS.

ELECTRON DOSE RATE

NO. NUCLIDE NUCLIDE DOSE RATE
LABEL NAME MILLIREHS/HR

$\begin{array}{llll}66 & \text { NB95H } & 0.161 \mathrm{E} & 06 \\ 65 & \text { ZR95 } & 0.134 \mathrm{E} & 06 \\ 67 & \text { NB95 } & 0.533 \mathrm{E} & 05\end{array}$

Tor AL

\section{PHOTON DOSE RATE}

NUCLIDE NOCLICE DOSE RATE
LABEL MAGE HILIERASAR

67
65
66

$0.776 \mathrm{E} 06$

$0.736 \mathrm{E} \quad 06$

0.573805

0.157 B 07

TOTAL DOSE RATE

$\begin{array}{ccc}\begin{array}{c}\text { NOCLIDE } \\ \text { LABEL }\end{array} & \begin{array}{c}\text { NUCLI DE } \\ \text { MAME }\end{array} & \begin{array}{c}\text { DOSE RATE } \\ \text { WILLIREES/HE }\end{array} \\ 65 & 2895 & 0.870806 \\ 67 & \text { NB95 } & 0.829806 \\ 66 & \text { NB95A } & 0.218 E 06 \\ & & 0.192 E 07\end{array}$


SAMPLE PROBLEA I FOR EXAEA III

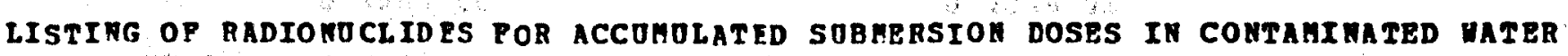

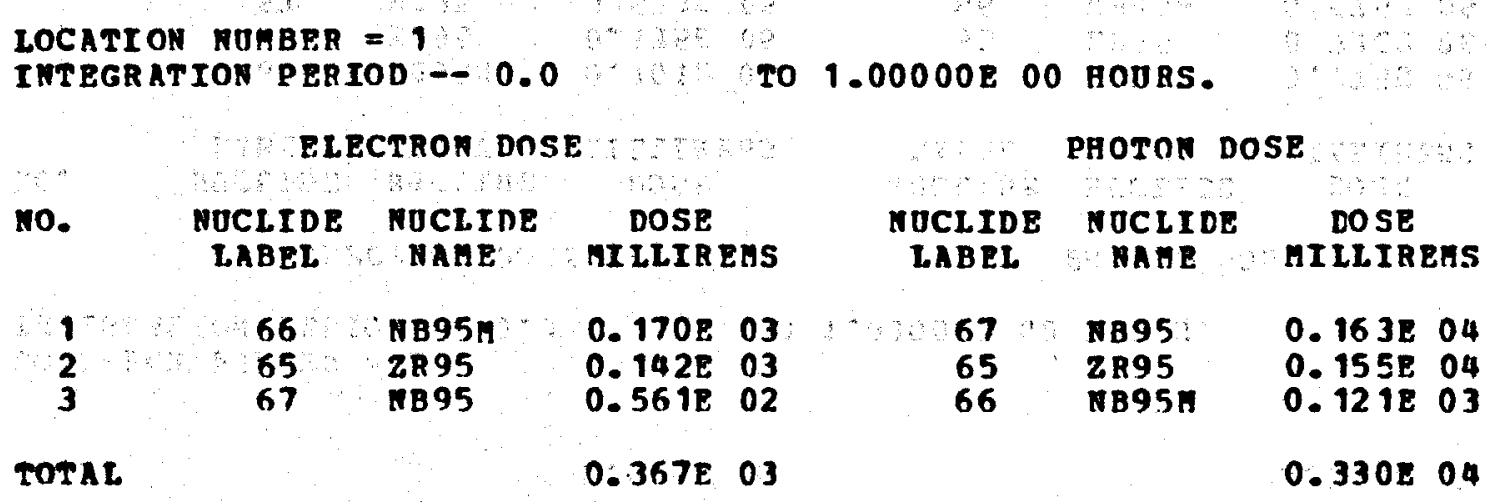

LOCATION RUABEA $=2$

INTEGRATTON PERIOD - 0.0

TO 1.00000 E 00 ROURS.

ELECTRON DOSE

no.

\begin{tabular}{|c|c|c|c|}
\hline $\begin{array}{c}\text { NUCLIDE } \\
\text { LABRL }\end{array}$ & $\begin{array}{l}\text { NUCLTDE } \\
\text { NAEE }\end{array}$ & $\begin{array}{c}\text { DOSE } \\
\text { GILIIRE }\end{array}$ & \\
\hline $\begin{array}{l}66 \\
65 \\
67\end{array}$ & $\begin{array}{l}\text { NB95N } \\
\text { ZR95 } \\
\text { NB95 }\end{array}$ & $\begin{array}{l}0.509 E \\
0.425 \mathrm{E} \\
0.168 \mathrm{E}\end{array}$ & $\begin{array}{l}03 \\
03 \\
03\end{array}$ \\
\hline
\end{tabular}

TOTAL
$0.110 \mathrm{P} \quad 04$
PHOTON DOSE

$\begin{array}{ccc}\text { NUCLIDE NUCLTDE } & \text { COSE } \\ \text { LABEL } & \text { NAME } & \text { HILIIAEHS } \\ 67 & \text { NB95 } & 0.489804 \\ 65 & \text { ZR95 } & 0.465 E 04 \\ 66 & \text { NB95 } & 0.363803 \\ & & 0.990804\end{array}$

TOTAL DOSE

\begin{tabular}{|c|c|c|}
\hline $\begin{array}{l}\text { NOCLIDE } \\
\text { LABEL. }\end{array}$ & $\begin{array}{c}\text { NOCLIDE } \\
\text { MAEE }\end{array}$ & $\begin{array}{c}\text { DOSE } \\
\text { ALLLIRBHS }\end{array}$ \\
\hline $\begin{array}{l}65 \\
67 \\
66\end{array}$ & $\begin{array}{l}\text { ZR95 } \\
\text { NB95 } \\
\text { NB95R }\end{array}$ & $\begin{array}{lll}0.1692 & 04 \\
0.169 E & 04 \\
0.291 E & 03\end{array}$ \\
\hline
\end{tabular}

G 
SARPLE PROBLEN I FOR EXREA ITI

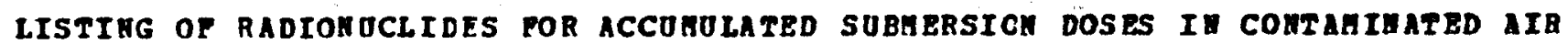

\begin{tabular}{|c|c|c|c|c|c|c|c|}
\hline \multirow[b]{2}{*}{ no. } & \multicolumn{4}{|c|}{ ELECTRON DOSE } & \multicolumn{3}{|c|}{ PHOTON DOSE } \\
\hline & $\begin{array}{l}\text { NUCLIDE } \\
\text { LABEI. }\end{array}$ & $\begin{array}{l}\text { NOCLIDE } \\
\text { NAHE }\end{array}$ & $\begin{array}{c}\text { DOSE } \\
\text { GILLIREH }\end{array}$ & US & $\begin{array}{l}\text { NOCLIDE } \\
\text { LABEL }\end{array}$ & $\begin{array}{l}\text { NOCLIDE } \\
\text { MAHE }\end{array}$ & $\begin{array}{c}\text { COSE } \\
\text { MILLIREHS }\end{array}$ \\
\hline $\begin{array}{l}1 \\
2 \\
3\end{array}$ & $\begin{array}{l}66 \\
65 \\
67\end{array}$ & $\begin{array}{l}\text { HB95 } \\
\text { 2R95 } \\
\text { WB95 }\end{array}$ & $\begin{array}{ll}0.323 E & 0 \\
0.2698 & 0 \\
0.1078 & 0\end{array}$ & $\begin{array}{l}06 \\
06 \\
06\end{array}$ & $\begin{array}{l}67 \\
65 \\
66\end{array}$ & $\begin{array}{l}\text { NB95 } \\
\text { Z R95 } \\
\text { NB95B }\end{array}$ & 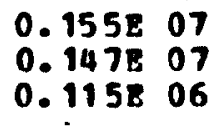 \\
\hline Tors & & & $0.698 \mathrm{E}$ & 06 & & & $0.314 E \quad 07$ \\
\hline
\end{tabular}

TO 1.00000 E 00 HOORS.

LOCATTOR MORBER $=2$

IMTEGRATION PERIOD - 0.0

PHOTON DOSE

ELECTROR DOSE

no.

$\begin{array}{ccc}\text { no. } & \begin{array}{c}\text { MOCLIDE } \\ \text { LABEL }\end{array} & \begin{array}{c}\text { NOCLIDE } \\ \text { NANE }\end{array} \\ 1 & 66 & \text { NB95S } \\ 2 & 65 & \text { 2R95 } \\ 3 & 67 & \text { NB95 }\end{array}$

DOSE MILIREHS

NOCLIDE NOCLIDE

cose

LABEL WAHE AIIIREHS

0. 161E 06

$0.135 E 06$

$67 \quad$ NB95

$0.775 B \quad 06$

652895

0.736806

$0.533 \mathrm{E} \mathrm{O5}$

66

MB95ก

0.575205

0.157807

TOTAL

$0.349 E \quad 06$

TOTAL DOSE

\begin{tabular}{|c|c|c|}
\hline $\begin{array}{l}\text { MOCLIDE } \\
\text { LABEL }\end{array}$ & $\begin{array}{l}\text { MOCLIDE } \\
\text { RABE }\end{array}$ & $\begin{array}{c}\text { DOSB } \\
\text { MILLIREHS }\end{array}$ \\
\hline $\begin{array}{l}65 \\
67 \\
66\end{array}$ & $\begin{array}{l}2895 \\
\text { MB95 } \\
\text { N895月 }\end{array}$ & 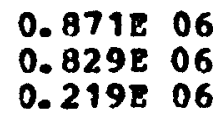 \\
\hline
\end{tabular}




\section{SAHPLE PROBLEM I FOR EXREA III}

LISTING OF RADTONOCLIDES POR ACCUMOLATED DOSES ABOVE A COATAMIMTED GROORD SORFACE

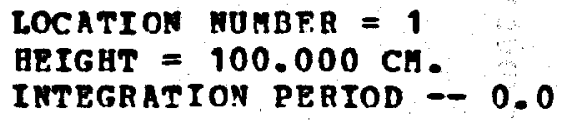

ELECTRON DOSE

$$
\text { no. }
$$$$
\begin{aligned}
& \text { NUCLIDE } \\
& \text { LABEL }
\end{aligned}
$$

$\begin{array}{lll}65 & \text { ZR } 95 & 0.114 \mathrm{E} 02 \\ 67 & \text { NB95 } & 0.108 \mathrm{E} 01 \\ 66 & 11895 & 0.622 \mathrm{E}-05\end{array}$

1
2
3

TOPAL
TO 1.0000OE OO HOORS.

PHOTON DOSE

\begin{tabular}{|c|c|c|}
\hline $\begin{array}{l}\text { IOCLIDE } \\
\text { I.ABEL. }\end{array}$ & $\begin{array}{l}\text { NUCLILE } \\
\text { NABE }\end{array}$ & $\begin{array}{l}\text { DOSE } \\
\text { MILIREMS }\end{array}$ \\
\hline $\begin{array}{l}67 \\
65 \\
66\end{array}$ & $\begin{array}{l}\text { NB95 } \\
\text { ZR95 } \\
\text { NE95 }\end{array}$ & $\begin{array}{ll}0.135 \mathrm{E} & 0.3 \\
0.129 \mathrm{E} & 03 \\
0.966 \mathrm{E} & 01\end{array}$ \\
\hline & & $0.274 E \quad 03$ \\
\hline
\end{tabular}

TO 1.00000 E 00 HOORS.
PHOTCN DOSE

\begin{tabular}{|c|c|c|}
\hline $\begin{array}{l}\text { NOCLIDE } \\
\text { LABEL }\end{array}$ & $\begin{array}{l}\text { NUCLICE } \\
\text { NABE }\end{array}$ & $\begin{array}{l}\text { DOSE } \\
\text { MILLIREAS }\end{array}$ \\
\hline $\begin{array}{l}67 \\
65 \\
66\end{array}$ & $\begin{array}{l}\text { NB95 } \\
\text { ZR95 } \\
\text { NB95 }\end{array}$ & 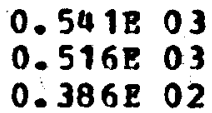 \\
\hline & & $0.110 \mathrm{~B} 04$ \\
\hline
\end{tabular}

TOTAL DOSE

$\begin{array}{ccc}\text { NOCLIDE } & \text { NOCLIDE } & \text { DOSE } \\ \text { LABEL } & \text { MAME } & \text { MILLIBEMS } \\ 65 & \text { ZR95 } & 0.140 E 03 \\ 67 & \text { NB95 } & 0.136 E 03 \\ 66 & \text { MB95M } & 0.966 E 01 \\ & & 0.286 \mathrm{E} 03\end{array}$

TOTAL DOSE

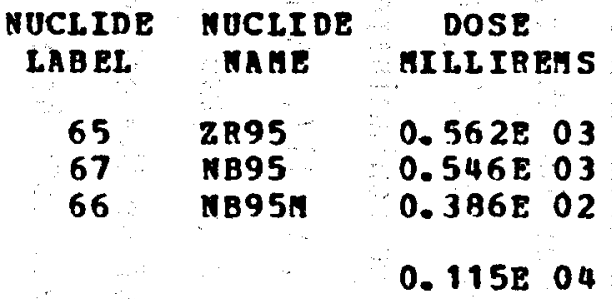

LOCATION NOHBER $=2$

IHTEGRATION PERIOD - 0.0

ELECTROON DOSE

\begin{tabular}{|c|c|c|c|}
\hline พก. & $\begin{array}{c}\text { NUCLIDE } \\
\text { LABRI }\end{array}$ & $\begin{array}{c}\text { NUCLIDE } \\
\text { FAFE }\end{array}$ & $\begin{array}{c}\text { DOSE } \\
\text { MILLIREMS }\end{array}$ \\
\hline $\begin{array}{l}1 \\
2 \\
3\end{array}$ & $\begin{array}{l}65 \\
67 \\
66\end{array}$ & $\begin{array}{l}\text { ZR95 } \\
\text { NB95 } \\
\text { NB95B }\end{array}$ & $\begin{array}{l}0.455 \mathrm{E} 02 \\
0.432 \mathrm{E} 01 \\
0.249 \mathrm{E}-04\end{array}$ \\
\hline ro? & & & $0.498 \mathrm{E}$ \\
\hline
\end{tabular}


Second Sample Problem for EXREM III

Determine the total dose equivalent from both beta and gamma radiation resulting from submersion in water and exposure $100 \mathrm{~cm}$ above a surface contaminated wi th the radionuclides SR-91, Y-91M, Y-91, $C D-117 M, C D-117, I N-117, S N-117 M$, and $W-187$. The radionuclides are the results of two environmental releases. One release occurs 1440 hours after the other. Calculate the total dose accumulated during the first 1500 hours following the first release.

The following chains describe the decay process of the radionuclides:
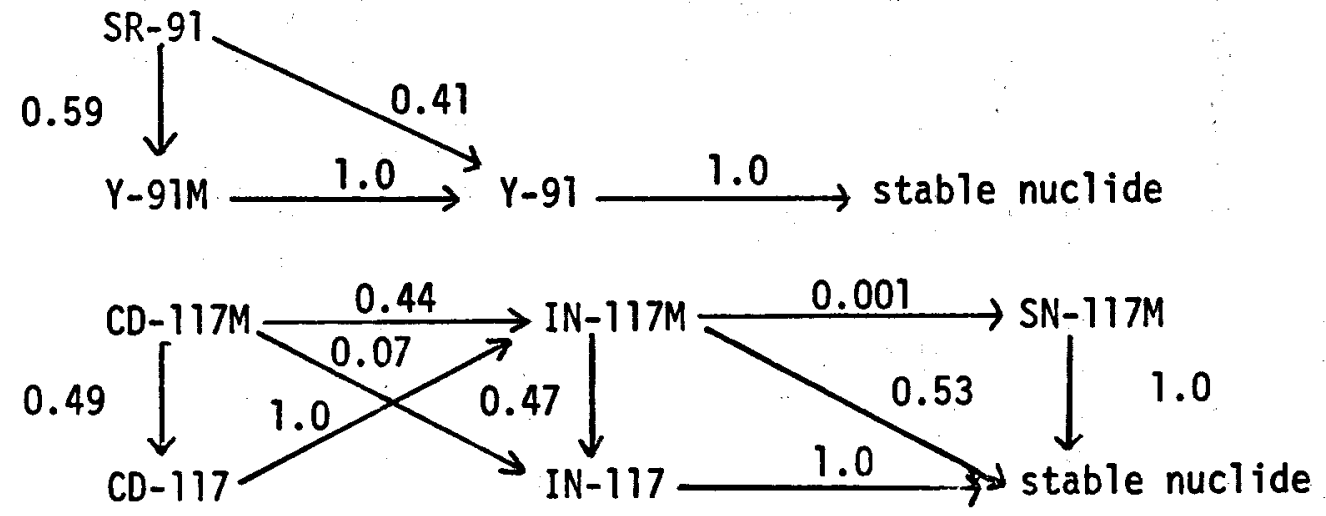

$$
W-187 \stackrel{1.0}{\longrightarrow} \text { stable nuclide }
$$

The format of the input cards containing the data necessary to describe the problem is given in Table 3 , and the computer tabulation of the output is given in Table 4 . 
005

$\begin{array}{rlllr}46 & 385 R 91 & 7.296-2 & 5 & 5 \\ 4739 Y 919 & 8.285-1 & 0 & 6 \\ 4839991 & 4.903-4 & 2 & 1 \\ 13348 C D 117 \% & 2.040-1 & 0 & 6 \\ 13448 C D 117 & 2.890-1 & 8 & 11 \\ 13549 \text { IN1174 } & 3.650-1 & 3 & 5 \\ 13649 \text { IN117 } & 9.240-1 & 1 & 3 \\ 137505 N 1174 & 2.060-3 & 0 & 3 \\ 291749187 & 2.900-2 & 8 & 11\end{array}$

000

$\begin{array}{rrrr}.61 & .07 & 1.09 & .33 \\ .3400 & .00211 .5450 & .998 \\ .55 & .03 & .63 & .38 \\ 1.93 & .07 & 2.230 & .12 \\ .95 & .04 & 1.62 & .23 \\ .74 & 1.6 & & \\ .43 & .005 & -44 & .0090 \\ .80 & .003 & 1.31 & -15\end{array}$

1. 37

.83
Table 3

5
6
1
6
11
5
3
3
11

.29

.09

23

8

2 NUCLID

5 NOCLID

5 NOCLID

O NOCLID

O NUCLID

0 NUCLID

O MUCLID

0 NUCLID

5 NOCLID END 1

$.04 \quad 2.67 \quad .27$

$1.77 \quad .53$

$.54 \quad .05$

.06

1.77

.16

1.86

$\begin{array}{ll}B & 46 \\ B & 48\end{array}$

$.09 B 1 \quad 134$

$B 2 \quad 134$

B 135

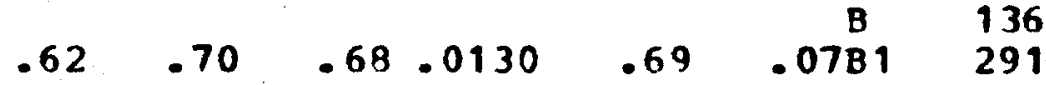

B2 291

EN D2

END3

000

$.534 .04483 .5488 .006151 .5507 .00205 .0127 .00908 .0146 .00308 .0164 .00035 \mathrm{E} 1$ .0016 .05243 .0003 .11740

$.0003 .10682 .0604 .01102 .0696 .00534 .0349 .00688 .0950 .00140 .1442 .00047 \mathrm{E} 1$

.0420 .00284 .1021 .00035 .1114 .00012 .0625 .15273 .1226 .03182 .1319 .0106182

47

47
291

.4081 .00373 .4682 .00089 .4774 .00030 .4408 .00024 .4800 .00028 000

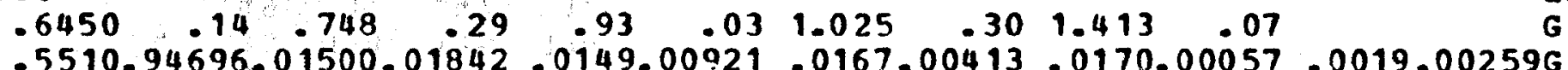

1.210 .002

281.570

.43

$\begin{array}{lll}.089 & .070 & .273 \\ .880 & .030 & .950\end{array}$

120.840

$.140 \quad 1.270$

.7001 .550

.310 .314

.0401 .052

$.160 \quad .345$

$.180 . .434$

150

.130

.0501 .304

$.190 \quad 1.577$

.170

$.310 \quad .087 \quad .822$

.020

.161

$.221 \quad .025 \quad .142$

E3 291

$\begin{array}{llllll}.565 & 1.00 & .161 & .885 & .026 & .115\end{array}$

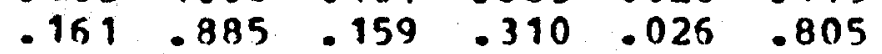

$.0720 .10682 .1066 .00275 .1137 .00109 .1342 .08984 .2062 .00064 .2391 .00097 G 1$

.2466 .00110 .2522 .00200 .4798 .23309 .5125 .01858 .5517 .04966 


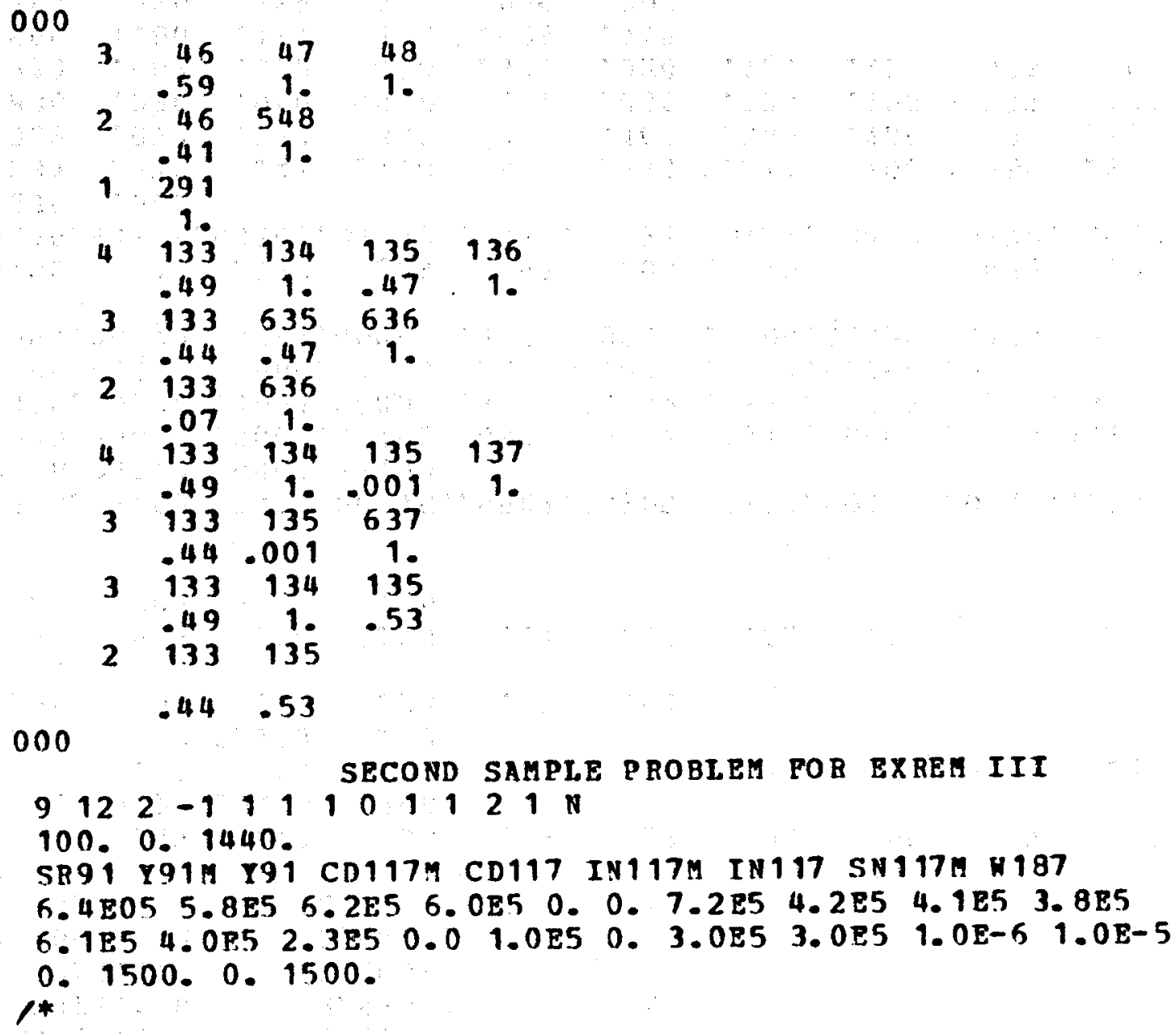

IHCO02I STOP 00000 
Table 4

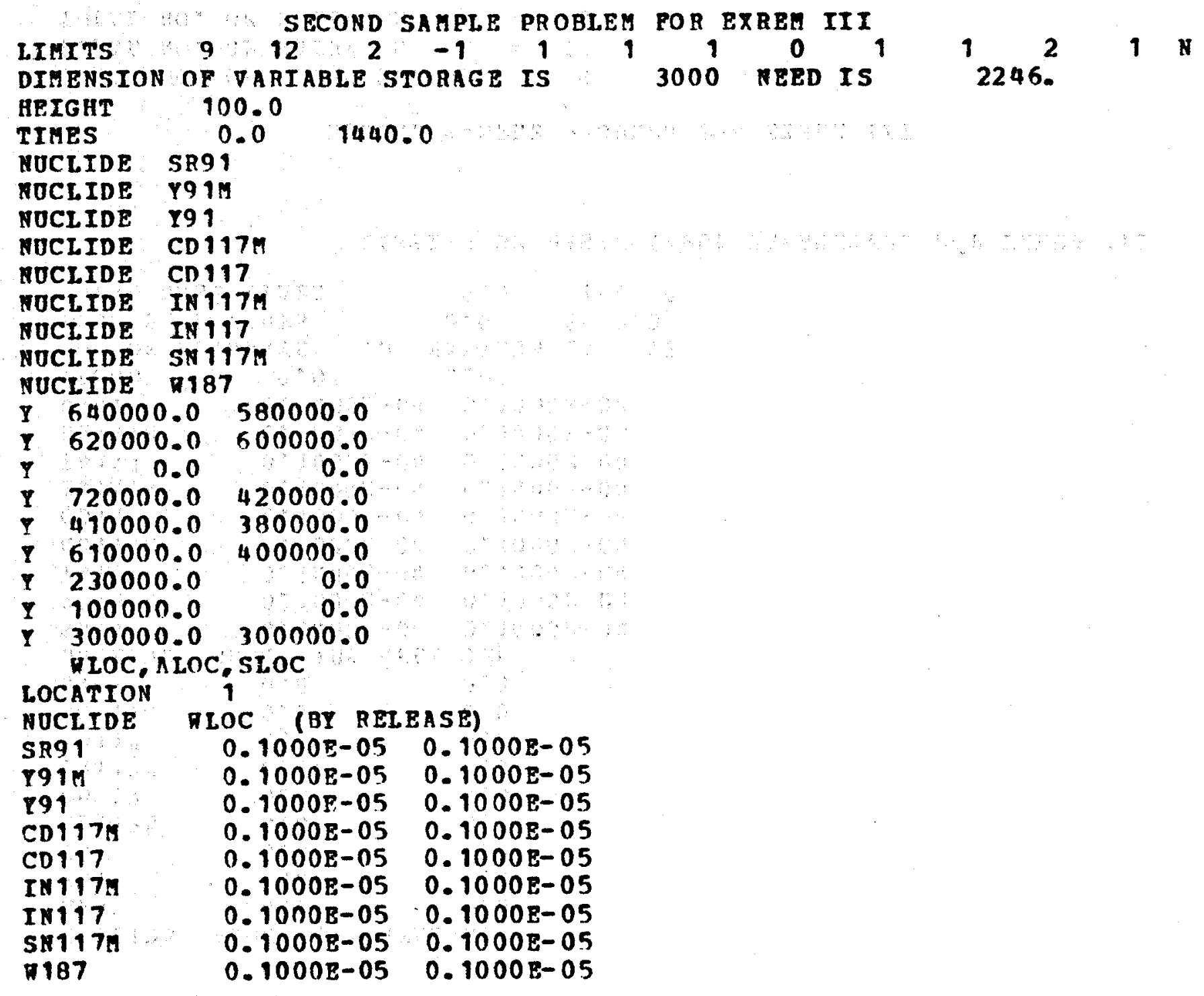




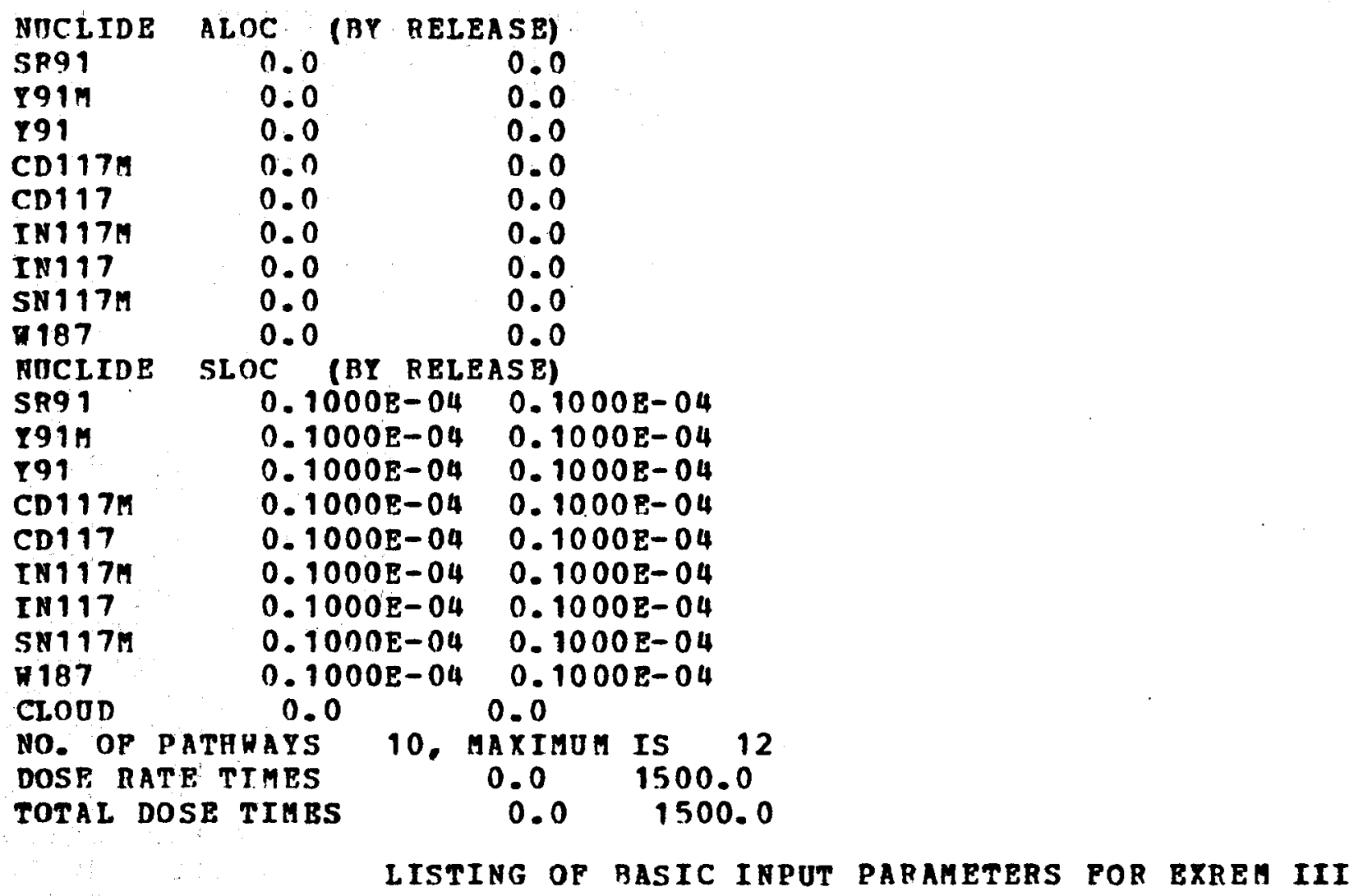

SECOND SAMPLE PROBLEM FOR EXREM IIT

TOTAL NO. OF RADIONUCLIDES $=9$

TOTAL NO. OP PATHWAYS $=10$

TOTAL NO. OP RELEASES $=2$

TOTAL NO. OF LOCATIONS $=1$ 
ESTIMATE DOSES FOR SUBRERSION IF VATER.

Estrate DOSEs POR EXPOSURE TO A SURFACE.

HEIGHT ABOTE GROUND SORFACE.

$$
\text { No. HPIGHT }
$$$$
\text { 1. } \quad 100.000
$$

TIME OP FACH RELRASE.

$$
\begin{aligned}
& \text { NO. RELEASE CLOND TIMR } \\
& 1 \text { TIHE (HRS) } \quad \text { (HRS) } \\
& \begin{array}{lll}
1 & 1440.0 & 0.0
\end{array}
\end{aligned}
$$

\begin{tabular}{|c|c|c|c|c|c|c|c|}
\hline Fnex & $\begin{array}{l}\text { ATOMIC } \\
\text { AUMBER }\end{array}$ & NAYE & DECAI CONSTANT & HO. BETA- & POSITRON & NUABER & CONVERSION/AUGER \\
\hline 46 & 38 & S R9 1 & $7.29600 \mathrm{E}-02$ & $\begin{array}{c}\text { PARTICLES } \\
5\end{array}$ & $\begin{array}{c}\text { PATI ICLES } \\
0\end{array}$ & $\begin{array}{c}\text { PHOTONS } \\
5\end{array}$ & $\begin{array}{c}\text { ELECTROHS } \\
0\end{array}$ \\
\hline 47 & 39 & Y91M & $8.28500 \mathrm{R}-01$ & 0 & 0 & 6 & 8 \\
\hline 48 & 39 & $Y 91$ & $4.90300 \mathrm{E}-04$ & 2 & 0 & 1 & 0 \\
\hline 133 & 48 & CD117M & $1000 \mathrm{E}-01$ & 0 & 0 & 6 & 0 \\
\hline 134 & 48 & CD117 & $00 E-01$ & 8 & 0 & 11 & $\mathbf{0}$ \\
\hline 135 & 49 & IN117K & $100 E-01$ & 3 & $\mathbf{0}$ & 5 & 0 \\
\hline 136 & 49 & IN117 & $100 \mathrm{E}-01$ & 1 & 0 & 3 & 0 \\
\hline 137 & 50 & Sะ117n & $100 E-03$ & 0 & 0 & 3 & 0 \\
\hline 291 & 74 & 187 & $100 E-02$ & B & 0 & 11 & 23 \\
\hline
\end{tabular}

RANIONUCLIDF IDENTIFICATION.

TIELD.

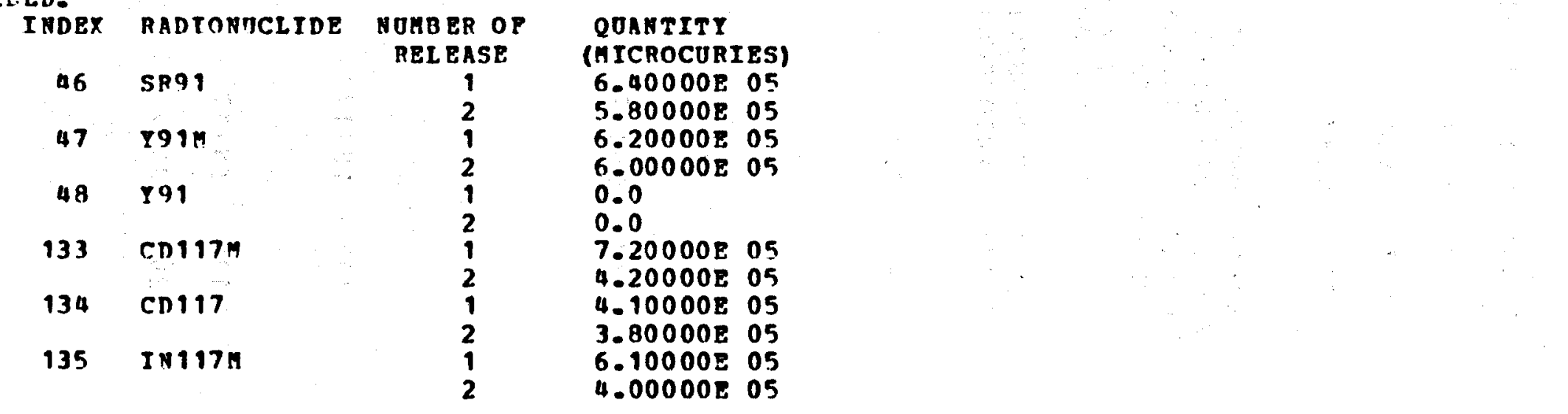


YIELD.

\begin{tabular}{|c|c|c|c|}
\hline INDEX & RADIONUCLIDE & $\begin{array}{l}\text { NUHBER OF } \\
\text { RELEASE }\end{array}$ & $\begin{array}{l}\text { QDANTITT } \\
\text { (HICROCURIES) }\end{array}$ \\
\hline 136 & IN 117 & $\begin{array}{l}1 \\
2\end{array}$ & $\begin{array}{l}2.30000 \mathrm{E} 05 \\
0.0\end{array}$ \\
\hline 137 & SN117日 & $\begin{array}{l}1 \\
2\end{array}$ & $\begin{array}{l}1.00000 \mathrm{E} 05 \\
0.0\end{array}$ \\
\hline 291 & $\$ 187$ & $\begin{array}{l}1 \\
2\end{array}$ & $\begin{array}{l}3.00000 E \\
3.00000 E\end{array}$ \\
\hline
\end{tabular}
LOCATION CORRECTION FACTOR.
FOR ALL RADIONUCLIDES AND FOR ALL RELEASES. LOCATION SUBHERSION SUBHERSION RXPOSURE NUHBER IN WATER IN AIR TO SORFACE $1 \quad 1.0000 \mathrm{E}-06 \quad 0.0^{(1 / \mathrm{CC})} \quad \begin{aligned} & (1 / \mathrm{SQ} \mathrm{CH}) \\ & 1.0000 \mathrm{R}-05\end{aligned}$

ENERGT AND INTENSITY FOR FACH BETA PARTICLE. INDEX RADIONUCLIDE NO. MAXIMUM ENERGY (HEV)

INTENS IT Y (FRACTION)

\begin{tabular}{|c|c|c|c|}
\hline 46 SR91 & $\begin{array}{l}1 \\
2 \\
3 \\
4 \\
5\end{array}$ & $\begin{array}{c}6.1000 \mathrm{E}-01 \\
1.0900 \mathrm{E} 00 \\
1.3700 \mathrm{E} 00 \\
2.0300 \mathrm{E} 00 \\
2.6700 \mathrm{E} 00\end{array}$ & $\begin{array}{l}0.07000 \\
0.33000 \\
0.29000 \\
0.04000 \\
0.27000\end{array}$ \\
\hline Y91 & $\begin{array}{l}1 \\
2\end{array}$ & $\begin{array}{l}3.4000 \mathrm{E}-01 \\
1.5450 \mathrm{E} 00\end{array}$ & $\begin{array}{l}0.00210 \\
0.99800\end{array}$ \\
\hline CD117 & $\begin{array}{l}1 \\
2 \\
3 \\
4 \\
5 \\
6 \\
7 \\
8\end{array}$ & $\begin{array}{l}5.0000 \mathrm{E}-01 \\
6.3000 \mathrm{E}-01 \\
8.3000 \mathrm{E}-01 \\
1.4700 \mathrm{E} 00 \\
1.7700 \mathrm{E} 00 \\
1.8600 \mathrm{E} 00 \\
1.9300 \mathrm{E} 00 \\
2.2300 \mathrm{E} 00\end{array}$ & $\begin{array}{l}0.03000 \\
0.38000 \\
0.09000 \\
0.06000 \\
0.16000 \\
0.09000 \\
0.07000 \\
0.12000\end{array}$ \\
\hline IN $117 M$ & $\begin{array}{l}1 \\
2 \\
3\end{array}$ & $\begin{array}{l}9.5000 \mathrm{E}-01 \\
1.6200 \mathrm{E} 00 \\
1.7700 \mathrm{E} 00\end{array}$ & $\begin{array}{l}0.04000 \\
0.23000 \\
0.53000\end{array}$ \\
\hline IN117 & 1 & $7.4000 \mathrm{E}-01$ & 1.00000 \\
\hline W187 & $\begin{array}{l}1 \\
2 \\
3 \\
4 \\
5 \\
6 \\
7 \\
8\end{array}$ & $\begin{array}{l}4.3000 \mathrm{E}-01 \\
4.4000 \mathrm{E}-01 \\
5.4000 \mathrm{E}-01 \\
6.2000 \mathrm{E}-01 \\
6.8000 \mathrm{E}-01 \\
6.9000 \mathrm{E}-01 \\
8.0000 \mathrm{E}-01 \\
1.3100 \mathrm{E} 00\end{array}$ & $\begin{array}{l}0.00500 \\
0.00900 \\
0.05000 \\
0.70000 \\
0.01300 \\
0.07000 \\
0.00300 \\
0.15000\end{array}$ \\
\hline
\end{tabular}


ENERGI AND INTENSITY POR EACE POSITRON. INDEX BADIONUCLIDE HO. HAXIMUH ENERGY (HEV)

INTENSITY (FRACTION)

IRTENSITY ENERG Y (MEV)

47 Y911

$\begin{array}{ll}1 & 5.3400 \mathrm{E}-01 \\ 2 & 5.4880 \mathrm{E}-01 \\ 3 & 1.5507 \mathrm{E} 00 \\ 4 & 1.2700 \mathrm{E}-02 \\ 5 & 1.4600 \mathrm{E}-02 \\ 6 & 1.6400 \mathrm{E}-02 \\ 7 & 1.6000 \mathrm{E}-03 \\ 8 & 3.0000 \mathrm{E}-04\end{array}$

$291 \quad 187$

1

2

3

4

5

6

7

8

9

10
3. $0000 \mathrm{E}-04$

6. $0400 \mathrm{E}-02$

6. $9600 \mathrm{E}-02$

3. $4900 \mathrm{E}-02$

9. 5000E-02

1. $4420 \mathrm{E}-01$

4. 2000E-02

1. $0210 \mathrm{E}-01$

1. $1140 \mathrm{E}-01$

6. $250 \mathrm{OE}-02$

1. $2260 \mathrm{E}-01$

1. $3190 \mathrm{E}-01$

1. $3450 \mathrm{E}-01$

1. $9460 \mathrm{E}-01$

2.0390E-01

1.6740E-01

2. 2750E-01

1.7490E-01

4. 0810E-01

4. 6820E-01

4.7740F-01

4. 4080E-01
4. $8000 \mathrm{E}-01$

(PRACTION)

0.04483

0.00615

0.00205

0.00908

0.00308

0.00035

0.05243

0.11740

0.10682

0.01102

0.00534

0.00688

0.00140

0.00047

0.00284

0.00035

0.00012

0.15273

0.03182

0.01061

0.00148

0.00043

0.00014

0.00068

0.00011

0.00033

0.00373

0.00089

0.00030

0.00024

0.00028

INTENSTTY (FRACTION)

ERE RG

(MEV)

46. SR91
0.14000

0.29000

0.03000

0.30000

0.07000 
47 I91M

5. 5100E-01

$1.5000 E-02$

$1.4900 \mathrm{E}-02$

$1.6700 \mathrm{E}-02$

1.7000E-02

$1.9000 \mathrm{E}-03$

$48 \quad Y 91$

133 CD117A

$134 \quad C D 117$

135 IN117M

136 IN117

137 SN117M
$1.2100 \mathrm{E} 00$

2.8100E-01

4. 3000E-01

8. 4000E-01

$1.2700 \mathrm{E} \mathrm{OO}$

$1.5500 \mathrm{E} \mathrm{OO}$

2. $4000 \mathrm{E}-02$

8. $9000 \mathrm{E}-02$

2.7300E-01

3. $1400 \mathrm{E}-01$

3. $4500 \mathrm{E}-01$

4. 3400E-01

$8.3200 \mathrm{E}-01$

8.8000E-01

9.5000E-01

1.052 OR 00

1. $3040 \mathrm{E} 00$

$1.5770 \mathrm{E}$ OO

11

$13.1000 \mathrm{E}-01$

8. 2200E-01

6. 2200E-01

$1.6100 \mathrm{E}-01$

2. $5000 \mathrm{E}-02$

5. 6500E-01

1.6100E-01

2.6000E-02

1.61008-01

1. 59008-01

2. 6000E-02
0.94696

0.01842

0.00921

0.00413

0.00057

0.00259

0.00200

0.57000

0.12000

0.14000

0.70000

0.15000

0.32000

0.07000

0.31000

0.16000

0.18000

0.13000

0.04000

0.03000

0.04000

0.05000

0.19000

0.17000

0.08700

0.02000

0.02000

0.22100

0.14200

1.00000

0.88500

0.11500

0.88500

0.31000

0.80500 
ENERGY AND INTENSTTY FOR EACH PHOTOH.

IRDEX RADIOROCLIDE NO.

ENERGY

INTENSITY

(MEV)

(FRACTION)

$291 \quad 187$

$\begin{array}{rr}1 & 7.2000 \mathrm{E}-02 \\ 2 & 1.0660 \mathrm{E}-01 \\ 3 & 1.1370 \mathrm{E}-01 \\ 4 & 1.3420 \mathrm{E}-01 \\ 5 & 2.0620 \mathrm{E}-01 \\ 6 & 2.3910 \mathrm{E}-01 \\ 7 & 2.4660 \mathrm{E}-01 \\ 8 & 2.5220 \mathrm{E}-01 \\ 9 & 4.7980 \mathrm{E}-01 \\ 10 & 5.1250 \mathrm{E}-01 \\ 11 & 5.5170 \mathrm{E}-01\end{array}$

0.10682

0.00275

0.00109

0.08984

0.00064

0.00097

0.00110

0.00200

0.23309

0.01858

0.04966

RADTONUCLIDE PATHWAYS.

PATHWAY POSITION INDEX FRACTION

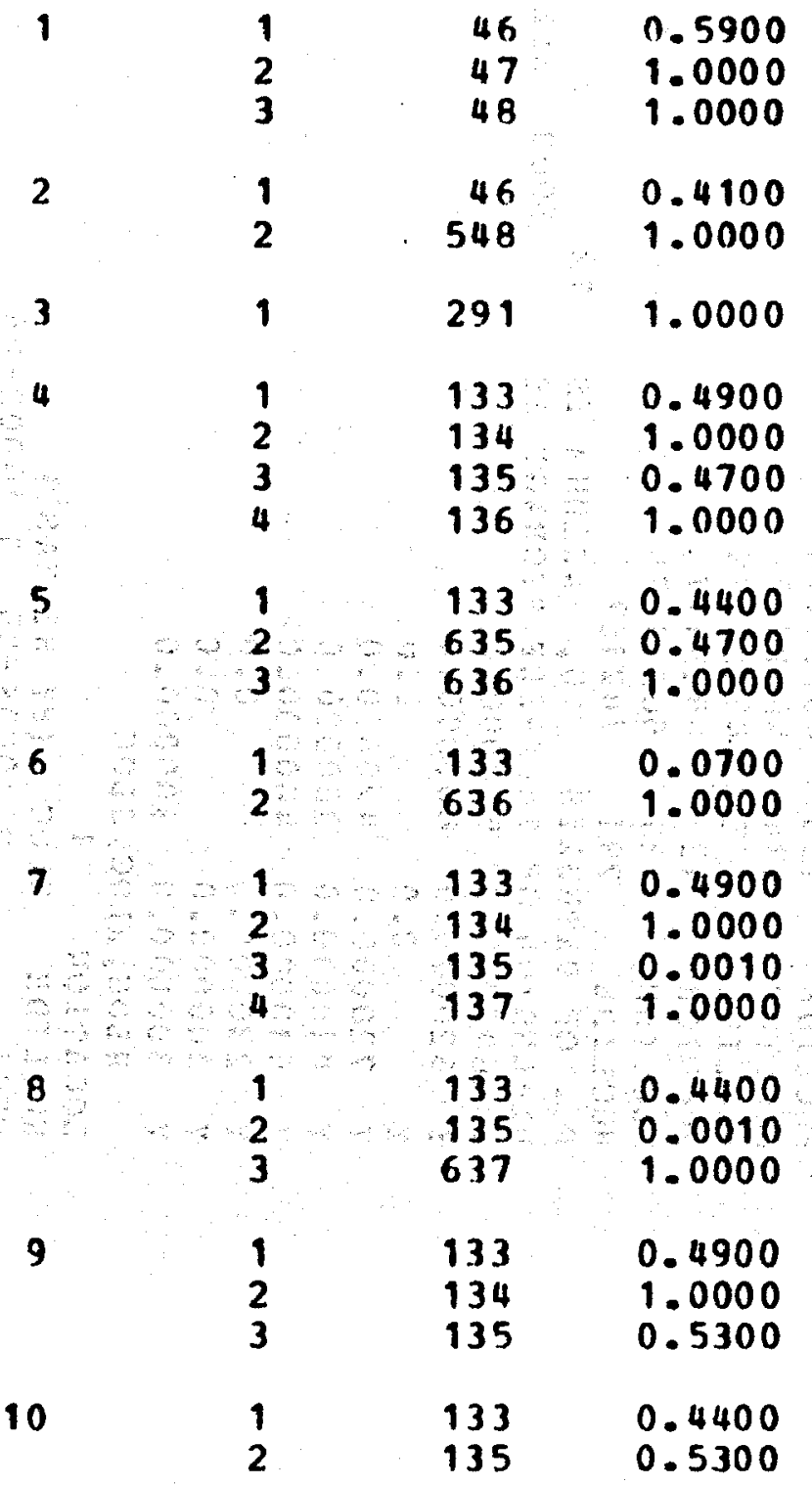


Table 4

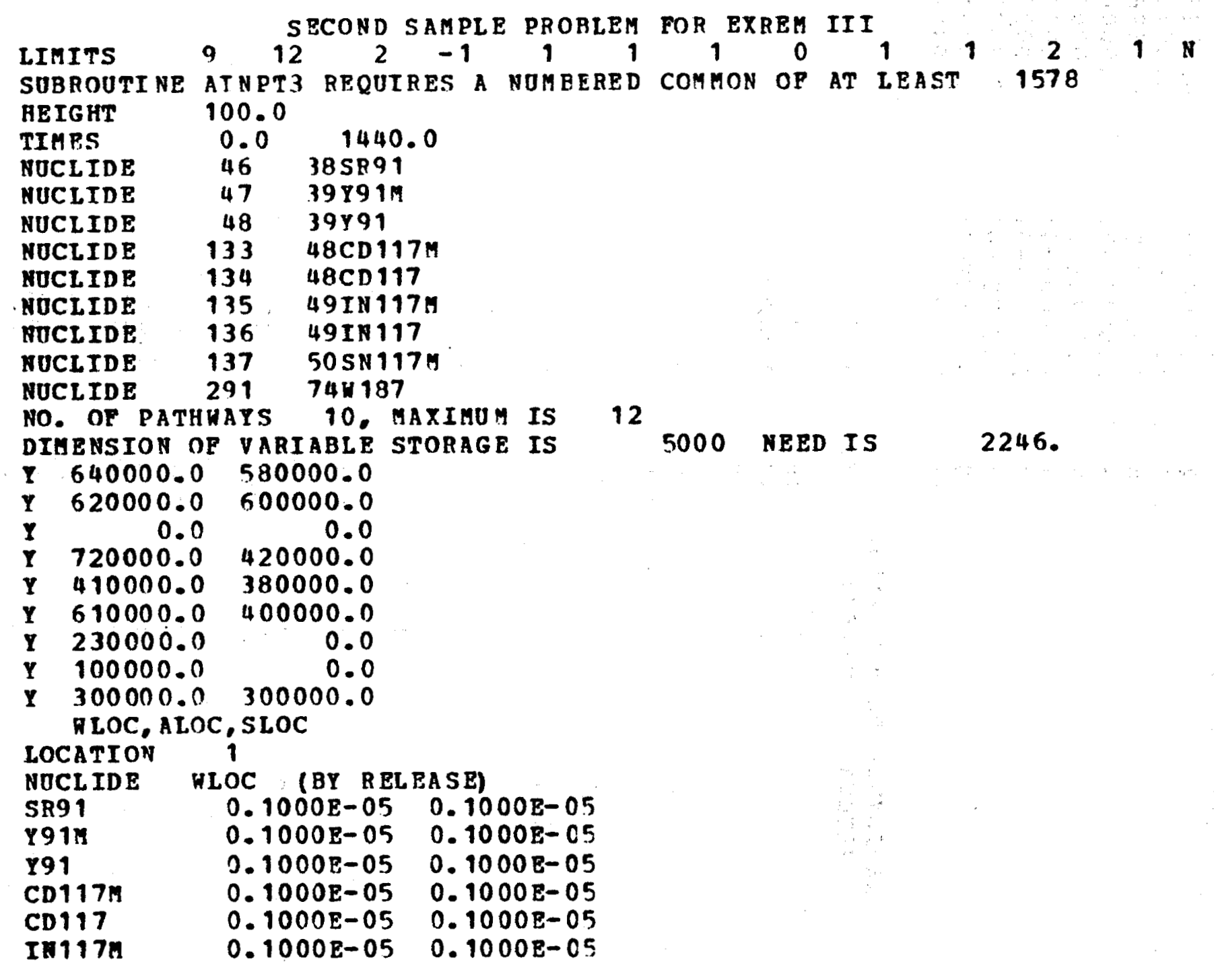




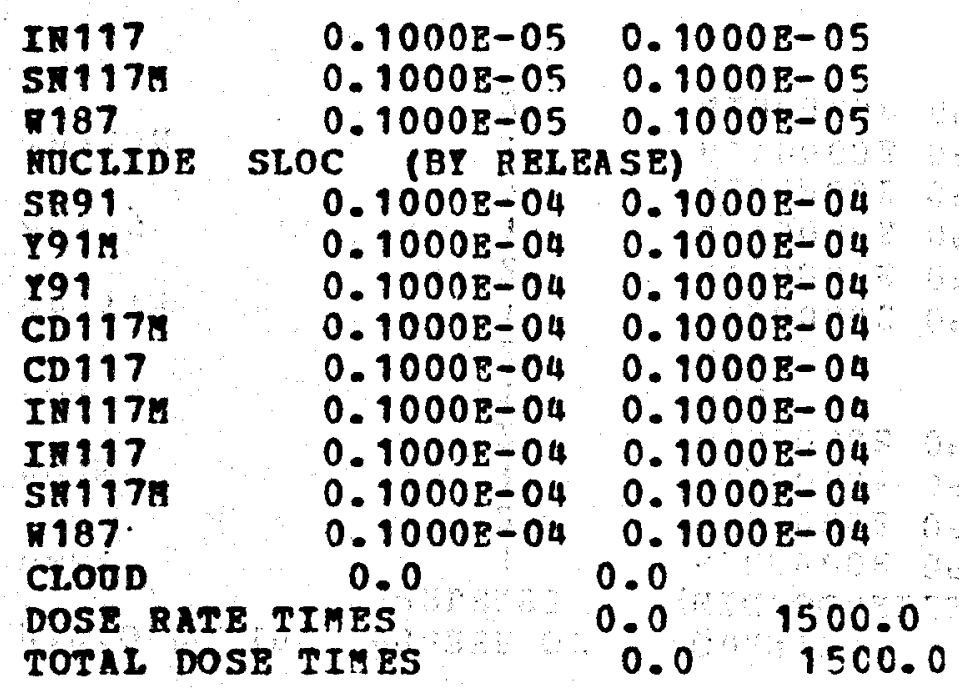

\section{SECOND SAMPLE PROBLEM FOR EXREM III}

$\begin{array}{ll}\text { TOTAI NO. OF RADIONUCLIDES }= & 9 \\ \text { TOTAL NO. OF PATHRATS } & =10 \\ \text { TOTAL NO. OF RELEASES } & =2 \\ \text { TOTAL NO. OF LOCATIONS } & =1\end{array}$

ESTIMATE DOSES FOR SUBMERSION IN NATER.

ESTIMATE DOSES FOR EXPOSURE TO A SURPACE.

HEIGAT ABOVE GROUND SURFACE.

NO. HEIGHT

(CA)
100.000 
TIME OP EACH RELEASF.

NO. RELEASE

CLOUD TIME

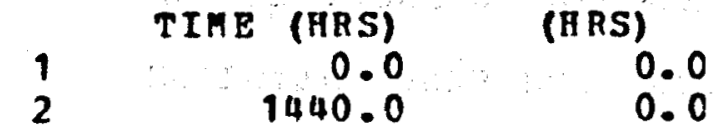

RADIONUCLIDE IDENTIFICATION.

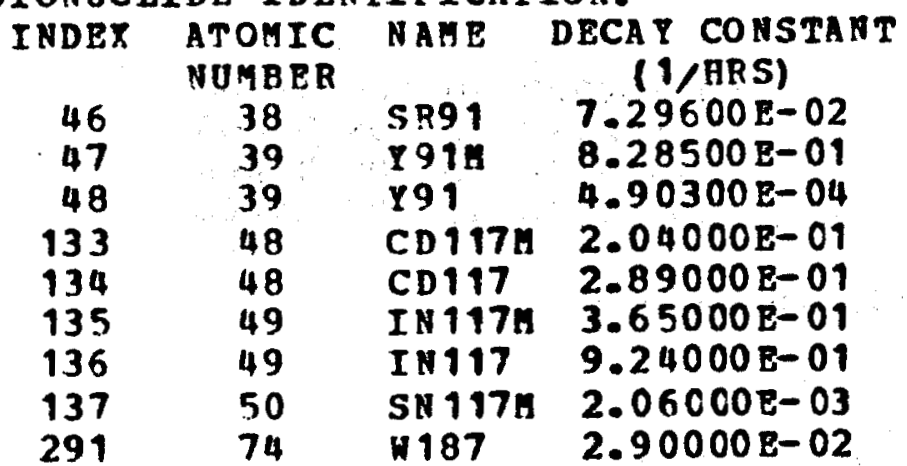

NO. BETA- POSITRON

PARTICLES PAETICLES

5
0
2
0
8
3
1
0
8

RU GBER CONVERSION/AUGER PHOTONS ET.ECTRONS

$\begin{array}{rr}5 & 0 \\ 6 & 8 \\ 1 & 0 \\ 6 & 0 \\ 11 & 0 \\ 5 & 0 \\ 3 & 0 \\ 3 & 0 \\ 11 & 23\end{array}$

TIELD.

\begin{tabular}{|c|c|c|c|}
\hline INDEX & RADIONUCLIDE & $\begin{array}{l}\text { NOHBER OF } \\
\text { RELEASE }\end{array}$ & $\begin{array}{l}\text { QUANTITI } \\
\text { (HICROCURIES) }\end{array}$ \\
\hline 46 & SR91 & $\begin{array}{l}1 \\
2\end{array}$ & $\begin{array}{ll}6.40000 E & 05 \\
5.80000 E & 05\end{array}$ \\
\hline 47 & Y911 & $\begin{array}{l}1 \\
2\end{array}$ & $\begin{array}{ll}6.20000 E & 05 \\
6.00000 E & 05\end{array}$ \\
\hline 48 & 791 & $\begin{array}{l}1 \\
2\end{array}$ & $\begin{array}{l}0.0 \\
0.0\end{array}$ \\
\hline 133 & $\operatorname{co117H}$ & $\begin{array}{l}1 \\
2\end{array}$ & $\begin{array}{ll}7.20000 \mathrm{E} & 05 \\
4.20000 \mathrm{E} & 05\end{array}$ \\
\hline 134 & CD 117 & $\begin{array}{l}1 \\
2\end{array}$ & $\begin{array}{lll}4.10000 E & 05 \\
3.80000 E & 05\end{array}$ \\
\hline 135 & IN & 1 & $\begin{array}{lll}6.10000 E & 05 \\
4.00000 E & 05\end{array}$ \\
\hline
\end{tabular}


YIELD.

I NDEX RADIOROCLIDE NOMBER OF QOAHTITY

136 IN117

RELEASE

(MICROCURIES)

137 SN117H

12.30000 E 05

$2 \quad 0.0$

291 พ187

1

$2 \quad 0.0$

$13.00000 \mathrm{E} 05$

$23.00000 \times 05$

LOCATION CORRECTION PACTOR.

FOR ALL RADIONOCLIDES AND FOR ALL BELEASES.

LOCATION

NOHBER

1

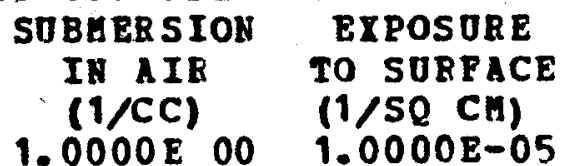

SOBEERSION EXPOSORE
IH AIR TO SORFACE

$1.0000 \mathrm{E} 00$

ENERGT AND INTENSITY FOR EACH BETA PARTICLE. INDEX RADIONOCLIDE HO. MAXIUUH ENERGY (MEV)

INTENSITY

(FRACTION)

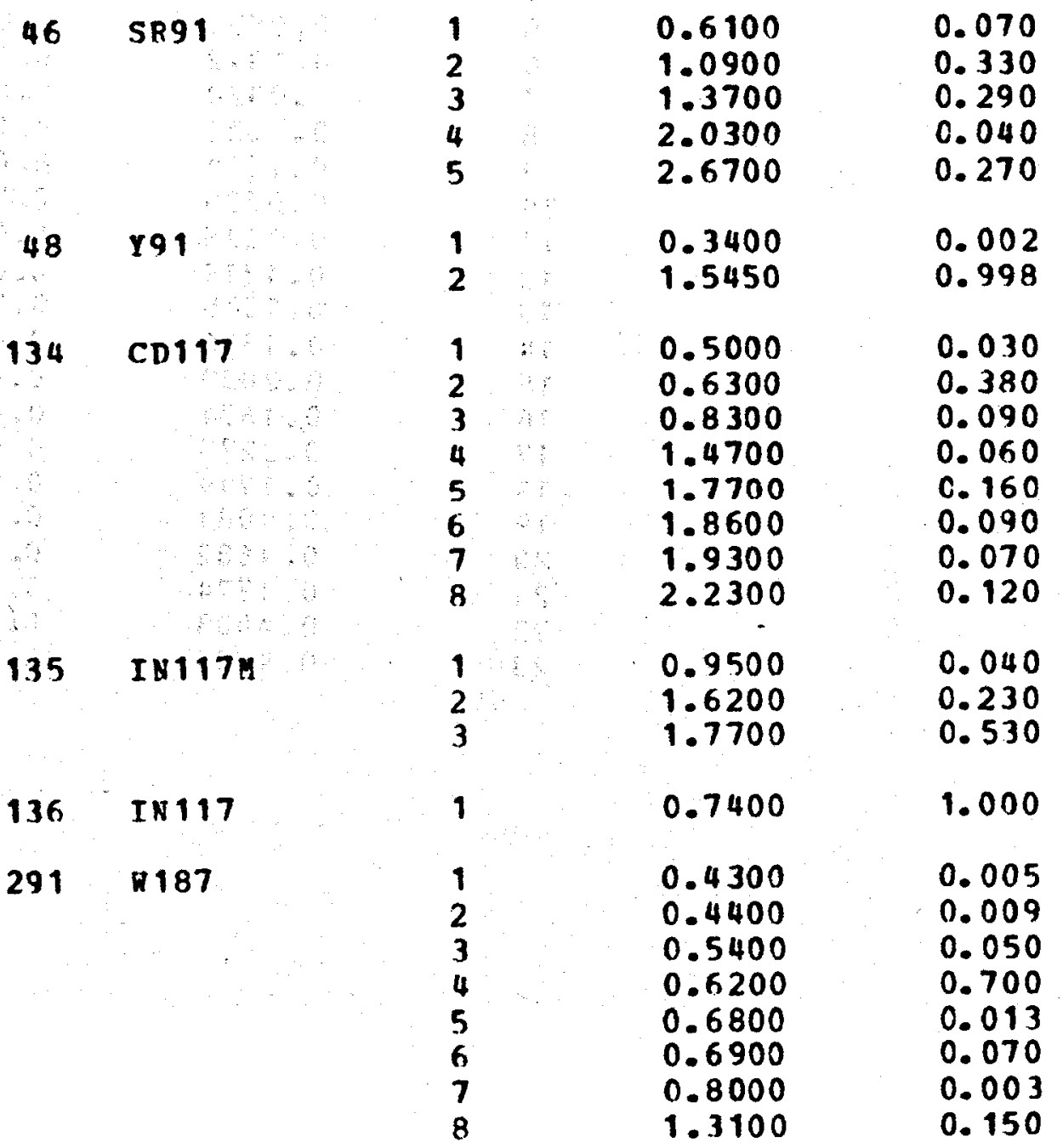


ERERGY AND INTEUSTTY FOR EACH POSITRON.

INDEX RADIONOCLIDE NO. MAXIMUM ENERGY

(MEV)

INTERSIT1

(FRACT IOM)

ENERGY AND TNTERSTTY FOR EACA ELECTRON.

INDEX RADIONOCLIDE NO. ENERGY

(HEV)

\section{INTENSTT I \\ (PRACTION)}

$47 \times 11$
1
2
3
4
5
6
7
8

291 พ187

\section{1}

2

3

5

6

7

8

9

10

11

12

13

14

15

16

17

18

19

20

21

22

23
0.5340

0.5488

1.5507

0.0127

0.0146

0.0164

0.0016

0.0003

0.0003

0.0604

0.0696

0.0349

0.0950

0.1442

0.0420

0.1021

0.1114

0.0625

0.1226

0.1319

0.1345

0.1946

0.2039

0.1674

0.2275

0.1749

0.4081

0.4682

0.4774

0.4408

0.4800
0.045

0.006

0.002

0.009

0.003

0.000

0.052

0.117

0.107

0.011

0.005

0.007

0.001

0.000

0.003

0.000

0.000

0.153

0.032

0.011

0.001

0.000

0.000

0.001

0.000

0.000

0.004

0.001

0.000

0.000

0.000 
EWERGI AND INTENSITI POR EACH PHOTON.

TRDEX RADIONOCLIDE HO.

$46 \quad$ SR9 1

1
2
3
4
5

$47 \quad$ Y91月

$$
\begin{aligned}
& 1 \\
& 2 \\
& 3 \\
& 4 \\
& 5 \\
& 6
\end{aligned}
$$

$48 \quad$ Y91

133 CD117K

$134 \quad \operatorname{CD} 117$

135 IN117

136 IN117

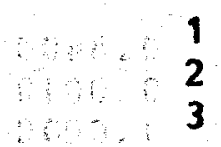

137 SN117\%

\section{ERE RG Y}

(HEV)

$$
\begin{aligned}
& 0.6450 \\
& 0.7480 \\
& 0.9300 \\
& 1.0250 \\
& 1.4130
\end{aligned}
$$

0.5510

0.0150

0.0149

0.0167

0.0170

0.0019

1.2100

0.2810

0.4300

0.8400

1.2700

1.5500

0.0240

0.0890

0.2730

0.3140

0.3450

0.4340

0.8320

0.8800

0.9500

1.0520

1. 3040

1.5770

0.3100

0.8220

0.6220

0.1610

0.0250

0.5650

0.1610

0.0260

0.1610

0.1590

0.0260

\section{INTENSITI}

(FRACTIOE)

0.140
0.290
0.030
0.300
0.070

0.947

0.018

0.009

0.004

0.001

0.003

0.002

0.570

0.120

0.140

0.700

0.150

0.320

0.070

0.310

0.160

0. 180

0.130

0.040

0.030

0.040

0.050

0.190

0.170

0.087

0.020

0.020

0.221

0.142

1.000

0.885

0.115

0.885

0.310

0.805 
EEERG AND INTENSTTY FOR EACH PHOTON.

INDEX RADIONUCLIDE NO.

$291 \quad \$ 187$
ENERGY

(HEV)

$\begin{array}{rl}1 & 0.0720 \\ 2 & 0.1066 \\ 3 & 0.1137 \\ 4 & 0.1342 \\ 5 & 0.2062 \\ 6 & 0.2391 \\ 7 & 0.2466 \\ 8 & 0.2522 \\ 9 & 0.4798 \\ 10 & 0.5125 \\ 11 & 0.5517\end{array}$

INTENSITI (FRACTIOE)
0.107
0.003
0.001
0.090
0.001
0.001
0.001
0.002
0.233
0.019
0.050

RADIONOCLIDE PATHATS.

PATHAAY POSITION INDEX PRACTIOH

\begin{tabular}{|c|c|c|c|}
\hline 1 & $\begin{array}{l}1 \\
2 \\
3\end{array}$ & $\begin{array}{l}46 \\
47 \\
48\end{array}$ & $\begin{array}{l}0.5900 \\
1.0000 \\
1.0000\end{array}$ \\
\hline 2 & $\begin{array}{l}1 \\
2\end{array}$ & $\begin{array}{r}46 \\
548\end{array}$ & $\begin{array}{l}0.4100 \\
1.0000\end{array}$ \\
\hline 3 & 1 & 291 & 1.0000 \\
\hline 4 & $\begin{array}{l}1 \\
2 \\
3 \\
4\end{array}$ & $\begin{array}{l}133 \\
134 \\
135 \\
136\end{array}$ & $\begin{array}{l}0.4900 \\
1.0000 \\
0.4700 \\
1.0000\end{array}$ \\
\hline 5 & $\begin{array}{l}1 \\
2 \\
3\end{array}$ & $\begin{array}{l}133 \\
635 \\
636\end{array}$ & $\begin{array}{l}0.4400 \\
0.4700 \\
1.0000\end{array}$ \\
\hline 6 & $\begin{array}{l}1 \\
2\end{array}$ & $\begin{array}{l}133 \\
636\end{array}$ & $\begin{array}{l}0.0700 \\
1.0000\end{array}$ \\
\hline 7 & $\begin{array}{l}1 \\
2 \\
3 \\
4\end{array}$ & $\begin{array}{l}133 \\
134 \\
135 \\
137\end{array}$ & $\begin{array}{l}0.4900 \\
1.0000 \\
0.0010 \\
1.0000\end{array}$ \\
\hline 8 & $\begin{array}{l}1 \\
2 \\
3\end{array}$ & $\begin{array}{l}133 \\
135 \\
637\end{array}$ & $\begin{array}{l}0.4400 \\
0.0010 \\
1.0000\end{array}$ \\
\hline 9 & $\begin{array}{l}1 \\
2 \\
3\end{array}$ & $\begin{array}{l}133 \\
134 \\
135\end{array}$ & $\begin{array}{l}0.4900 \\
1.0000 \\
0.5300\end{array}$ \\
\hline 10 & $\begin{array}{l}1 \\
2\end{array}$ & $\begin{array}{l}133 \\
135\end{array}$ & $\begin{array}{l}0.4400 \\
0.5300\end{array}$ \\
\hline
\end{tabular}


SECOND SAHPLE PROBLEA FOR EXAE III

IISTIKG OP RADIONOCLIDES FOR SOAHERSON DCSE RATES IN CONTAMIMATED DATER

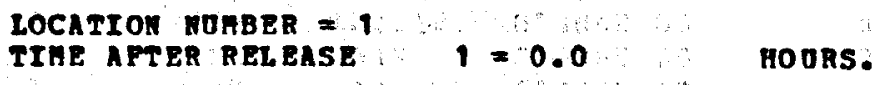

ELECTRON DOSE RATE

no.

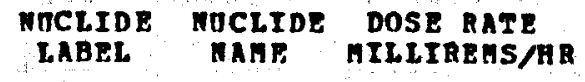

\section{SR91}

IN117\%

0.428803

0.334803

0.209803

"187

0.8428 .02

0.632202

0.204202

Y9 in

T91

0.0

133 CD117

0.0

SN1174

0.1148 on

133
46
134
47
136
135
291
137
48

TOTaL.
PHOTO DOSE RATE

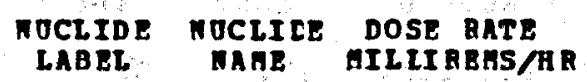

CD117
SR9
CD117
Y914
I 1117
I 1117n
Q187
S4117A
Y91

991

$0.224 E 04$
0.101804
0.810803
0.691203
0.349803
0.124803
$0.109 E 03$
0.454802
0.0

0.538 e 04
TOTAL DOSE RATE

TOCLIDE MOCLIDE DOSE RATE
LABEL

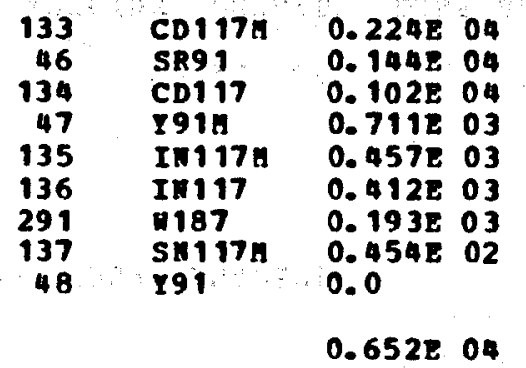

LISTTIG OP RADTONUCLIDES POR DOSE RATES AEOVE A CONTANINATED GROOND SURPACE

LOCATION MURBER $=1$

TTME ATTER RELEASE $1=0.0$

ELECTRON DOSE RATE

no. NOCLIDE NUCLIDE DOSERATE
LABEL MATE HILIIREAS/HR

15
135
134
291
136
47
48
133
137

SR91

Tx117日

CD 117

$0.962 E^{\circ}$ O4

$0.911 E 04$

$0.4558 \mathrm{CA}$

ब187

IN117

0.6598 O3

Y91ก

0.417803

791

0.7868 .02

CDi17

0.0

SN1174

0.0

$0.244 E 05$
HOORS.

PHOTON DOSE RATE

TOTAL DOSE RATE

NOCLIDE NOCLICE DOSE RATE NOCLIDE NOCLIDE DOSE RATE

LABEL MAME MILIIREMS/HB LABEL TAHE MIIIREAS/RE

133
46
134
47
136
135
291
137
48

CDi17n 0.1798 on

SR91 $0.82 \mathrm{CE}$ O3

CD117 0.635203

Y914 0.589203

$\begin{array}{lll}\text { IX117 } 0.2928 & 03\end{array}$

IH117日 0.114203

$187 \quad 0.904802$

Sแ117! 0.477202

Y91

0.0

46
135
134
133
291
136
47
137
48

SR91

INIITH $0.923 \mathrm{E}$ O4

CD117 0.5198 04

CDI17E 0.179E O4

11870.749803

IE117 0.709203

Y91月 $0.668 \mathrm{~B} 03$

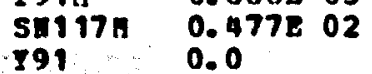

0.0

0.438804

$0.288 E 05$ 
LISTING OF RADIONUCLIDES POR SUEAERSON DCSE RATES IN CONTAMIEA TED MATEA

LOCATION MURBER $=1$

TIME APTER RELEASE $1=1.50000 \mathrm{0} 03$ HOORS.

ELECTRON DOSE RATE

no.

1
2
3
4
5
6
7
8
9

TOTAL
PHOTON DOSE RATE

NOCLIDE
IABEL
291
46
47
137
48
136
134
133
135

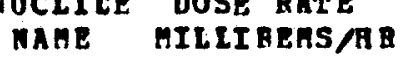

1187

SR91

T910

Sพ117

I91

IN117

CD 117

CD117\%

IN117\%
0.19 IE 02

0.115802

0.525801

0.207201

$0.32 \mathrm{BE}-01$

$0.9098-02$

$0.666 \mathrm{E}-02$

$0.6328-02$

$0.195 \%-02$

0.380202
TOTAL DOSE RATE

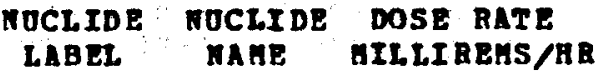

291
46
47
48
137
136
134
135
133

4187

SR91

r918

791

Sพ117n

IN117

CD117

I117n

CD117H

$0.339 \mathrm{E} 02$

0.540201

$0.403 E 01$

$0.207 E 01$

$0.107 \mathrm{E}-01$

$0.838 E-02$

$0.723 E-02$

$0.632 \mathrm{~B}-02$

$0.238 \mathrm{E} \quad 02$

$0.618 E 02$

LISTING OP RADIONOCLICES FOR DOSE RATES ABOVE A COATAMINATED GROUND SURFACE

LOCATION NOMBER $=1$

HEIGHT $=100.000 \mathrm{CH}$.

TIME AFTER RELEASE

$1=1.500 \mathrm{COE} 03$ HOURS.

BLECTRON DOSE RATE

PHOTOR DCSE RATE

NOCLIDE WUCLIDE DOSE RATE
LABFL

291
46
48
47
135
134
136
133
137

TOTAL

$\begin{array}{ll}1187 & 0.116 \mathrm{E} 03 \\ \text { SA91 } & 0.109 \mathrm{E} 03 \\ \text { I91 } & 0.108 \mathrm{E} 03 \\ \text { T917 } & 0.598 \mathrm{E} 00 \\ \text { IN117H } & 0.144 \mathrm{E} 00 \\ \text { CD117 } & 0.374 \mathrm{E}-01 \\ \text { IN117 } & 0.109 \mathrm{E}-01 \\ \text { CD } 117 \mathrm{H} & 0.0 \\ \text { SN117H } & 0.0 \\ & 0.334 \mathrm{E} 03\end{array}$

HOCLIDE NOCLIEE DOSE RATE
LABEL MAHE MILLIBEAS/HR

291

46

47

137

48

136

134

133

135

W187
SR91
Y911
SN117
Y 91
I 1117
CD 117
CD 117 B
I H117

0.933201

0.448801

0.218801

$0.256 \mathrm{E}-01$

$0.762 \mathrm{~B}-02$

$0.522 \mathrm{E}-02$

$0.505 \mathrm{E}-02$

$0.181 \mathrm{E}-02$

0.319202
TOTAL DOSE AATE

\begin{tabular}{|c|c|c|}
\hline $\begin{array}{c}\text { NOCLIDE } \\
\text { LABEL }\end{array}$ & $\begin{array}{l}\text { NOCLIDE } \\
\text { WARE }\end{array}$ & $\begin{array}{l}\text { DOSE RATE } \\
\text { WIILIREHS/HE }\end{array}$ \\
\hline $\begin{array}{r}291 \\
46 \\
48 \\
47 \\
137 \\
135 \\
134 \\
136 \\
133\end{array}$ & $\begin{array}{l}\text { R187 } \\
\text { SR91 } \\
\text { Y91 } \\
\text { Y914 } \\
\text { SN117n } \\
\text { IN117n } \\
\text { CD117 } \\
\text { IN1 17 } \\
\text { CD } 117 n\end{array}$ & 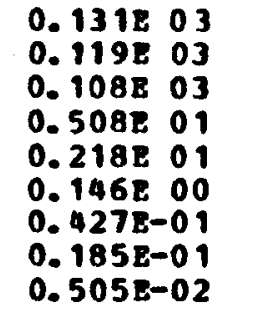 \\
\hline & & $0.366 E 03$ \\
\hline
\end{tabular}


LISTIMG OP RADIONOCLIDES FOR ACCONULATED SOBHERSION DOSES In COATAMTHAED MATER

LOCATIOH MUABER $=1$

INTEGRATION PERIOD -- 0.0

ELECTRON DOSE

no.

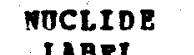

OCLIDE

DOSE

LABEL NAME MILLIREHS

1
2
3
5
5
6
7
8

$\operatorname{rota} 1$

$0.279 E$ CA

$0.170 \mathrm{E}$ O4

0. $370 \mathrm{E} \quad 03$

0.0

$0.309 E 05$
TO 1.50000E 03 noORs.

PHOTOn DOSE

\begin{tabular}{|c|c|}
\hline $\begin{array}{c}\text { NOCLIDE } \\
\text { LABEL }\end{array}$ & $\begin{array}{l}\text { HUCLICE } \\
\text { MATE }\end{array}$ \\
\hline $\begin{array}{r}46 \\
137 \\
133 \\
47 \\
134 \\
136 \\
291 \\
135 \\
48\end{array}$ & 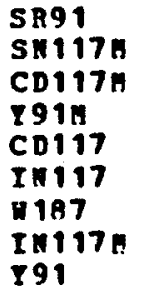 \\
\hline
\end{tabular}

DOSE

0.263805

0.210805

0.174805

0.126805

$0.108 \mathrm{~B} 05$

0.937204

0.685204

I91

0.265802

0.107206
Total Dose

\begin{tabular}{|c|c|c|}
\hline $\begin{array}{l}\text { UCLIDE } \\
\text { LABEL }\end{array}$ & $\begin{array}{l}\text { NOCLIDE } \\
\text { MARE }\end{array}$ & $\begin{array}{l}\text { DOSE } \\
\text { GILLIREE }\end{array}$ \\
\hline $\begin{array}{r}46 \\
137 \\
133 \\
134 \\
47 \\
291 \\
136 \\
135 \\
48\end{array}$ & 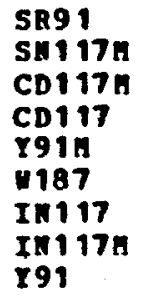 & $\begin{array}{l}0.374 E \\
0.210 E \\
0.174 E \\
0.136 E \\
0.129 E \\
0.121 E \\
0.111 E \\
0.884 E \\
0.325 E\end{array}$ \\
\hline
\end{tabular}

$0.138 \mathrm{~B} 06$

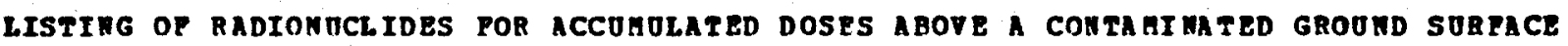

LOCATION MOMBER $=1$

HEIGHT $=100.000 \mathrm{CH}$

IMTEGRATTON PERTOD - 0.0

TO 1.50000803 HOOBS.

ELECTRON DOSE

no.

FOCLTDE NUCLIDE
LABEL NARE

DOSE MILLIREAS

1
2
3
4
5
6
7
8
9

46

SR 91 IN117n

$r 91$

CD 117

เ187

IN 117

I9 In

CD 1174

SH 117M

TOTAL
$0.250 \mathrm{E} \quad 06$ 0.176806 $0.870 \mathrm{E} 05$

0.607 E 05

0.414805

$0.112 \mathrm{E} 05$

$0.143 E$ O4

0.0

$0.628 E$ O6
PHOTON DOSE

\begin{tabular}{|c|c|c|}
\hline $\begin{array}{l}\text { NOCLIDE } \\
\text { LABEL }\end{array}$ & $\begin{array}{l}\text { MOCLIDE } \\
\text { MARE }\end{array}$ & $\begin{array}{c}\text { MSE } \\
\text { HILLIREHS }\end{array}$ \\
\hline $\begin{array}{r}137 \\
46 \\
133 \\
47 \\
134 \\
136 \\
291 \\
135 \\
48\end{array}$ & 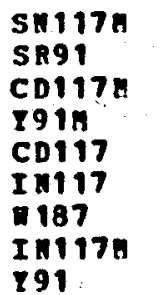 & 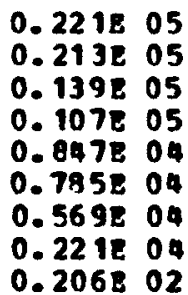 \\
\hline
\end{tabular}

TOTAL DOSE

\begin{tabular}{|c|c|c|}
\hline $\begin{array}{l}\text { IOCLIDE } \\
\text { LABEL }\end{array}$ & $\begin{array}{l}\text { MOCLIDE } \\
\text { RARE }\end{array}$ & $\begin{array}{c}\text { DOSE } \\
\text { MILLIRES }\end{array}$ \\
\hline $\begin{array}{r}46 \\
135 \\
48 \\
134 \\
291 \\
137 \\
136 \\
133 \\
47\end{array}$ & $\begin{array}{l}\text { SR91 } \\
\text { In117n } \\
\text { Y91 } \\
\text { CD117 } \\
0187 \\
\text { SN117n } \\
\text { In117 } \\
\text { CD117n } \\
\text { I91月 }\end{array}$ & $\begin{array}{l}0.271 E \\
0.178 E \\
0.870 z \\
0.692 E \\
0.4718 \\
0.2218 \\
0.1912\end{array}$ \\
\hline
\end{tabular}

0.720806 
APPENDIX B

DATA BASE (SEPT 1973)

The nuclear data base made available with the code in September 1973 includes 189 nuclides comprising 141 pathways. The data were assembled in 1973 from five sources and are numbered accordingly on the NUCLID cards. The five sources are:

1. M. J. Martin, Radioactive Atoms, Supplement 1. ORNL-4293. Oak Ridge National Laboratory. (to be published)

2. M. J. Martin and P. H. Blichert-Toft, "Radioactive Atoms, Auger-Electron, $\alpha-, \beta-, \gamma-$, and X-Ray Data," Nuclear Data Tables, Section A, 8(1-2), 1-198 (1970).

3. L. T. Dillman, "Radionucl ide Decay Schemes and Nuclear Parameters for Use in Radiation-Dose Estimation," Medical Internal Radiation Dose Committee Pamphlet No. 4., J. Nuclear Medicine, Supplement No. 2., Vol. 10 (March 1969).

4. L. T. Dillman, "Radioactive Decay Schemes and Nuclear Parameters for Use in Radiation-Dose Estimation, Part 2," MIRD Committee Pamphlet No. 6, J. Nuclear Medicine, Supplement No. 4, Vol. 11 (March 1970).

5. Unpublished data of the Information Center for Internal Exposure, Oak Ridge National Laboratory. Some of the data were especially prepared at our request by F. C. Von der Lage. 
If data for a given nuclide were available in more than one of the sources, the source with the lower number was selected. In cases where there were more than 15 beta rays, 30 photons, or 30 conversion/Auger electrons, data were generally combined. That is, for two or more spectral lines, a representative energy was chosen and the abundance was combined to result in the same total energy as if the separate lines were used.

The data library in its most current form is available from the Radiation Shielding Information Center under the name DECAYREM. 
Internal Distribution

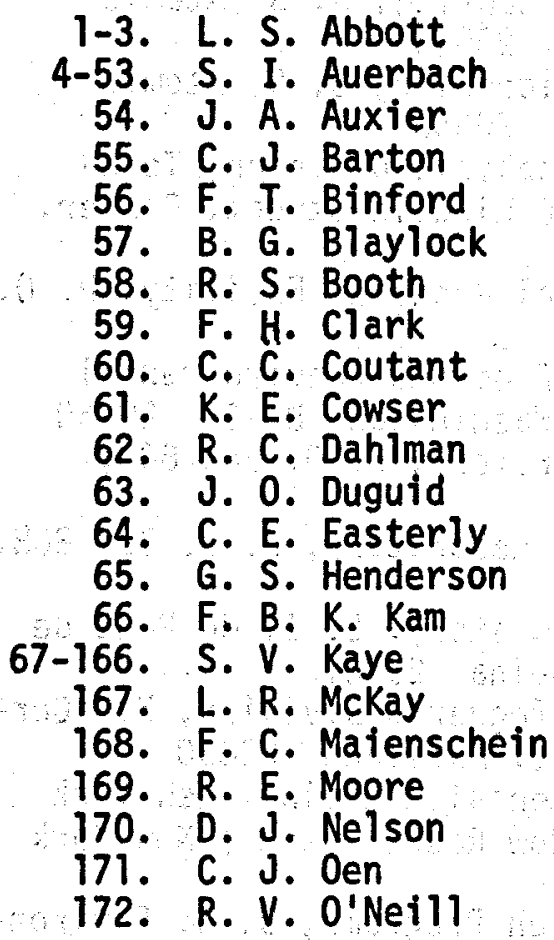

173. R. E. Reichle

174. P. S. Rohwer

175. E. G. Struxness

176. J. R. Trabalka

177-186. D. K. Trubey

187. W. D. Turner

188. R. I. Van Hook

189. H. A. Vanderploeg

190. J. P. Witherspoon

191. A. Zucker

192. H. Feshbach (consultant)

193. P. E. Fox (consultant)

194. C. R. Meh1 (consultant)

195. H. T. Motz (consultant)

196-205. RSIC

206-215. Mathematics Division Library

216-217. Central Research Library

218. ORNL - Y-12 Technical Library Document Reference Section

219-228. Laboratory Records Department

229. Laboratory Records, ORNL-R.C.

230. ORNL Patent Office

\section{External Distribution}

231-232. Nathaniel F. Barr, Division of Biomedical and Environmental Research, U. S. Atomic Energy Commission, Washington, D. C. 20545

233. Raymond D. Cooper, Division of Biomedical and Environmental Research, U. S. Atomic Energy Comission, Washington, D. C. 20545

234. Douglas Grahn, Division of Biomedical and Environmental Research, U. S. Atomic Energy Commission, Washington, D. C. 20545

235. Rudolf J. Engleman, Division of Biomedical and Environmental Research, U. S. Atomic Energy Commission, Washington, D. C. 20545

236. Jacob Kastner, Radiological Assessment Branch, Directorate of Licensing, U. S. Atomic Energy Commission, Washington, D. C. 20545

237. Michael A. Parsont, Radiological Assessment Branch, Directorate of Licensing, U. S. Atomic Energy Commission, Washington, D. C. 20545

238. D. S. Barth, National Environmental Research Center, EPA, P. 0. Box 15027, Las Vegas, Nevada 89114 
239. K. Z. Morgan, School of Nuclear Engineering, Georgia Institute of Technology, Atlanta, Georgia 20332

240-241. Carl Gamertsfelder, Directorate of Licensing, U. S. Atomic Energy Commission, Washington, D. C. 20545

242. Reginald L. Gotchy, Directorate of Licensing, U. S. Atomic Energy Commission, Washington, D. C. 20545

243. John E. Hardaway, Surveillance and Analysis Division, Technical Support Branch, Suite 900, 1860 Lincoln Street, Denver, Colorado 80203

244. Jon A. Broadway, Eastern Environmental Research Facility, P. 0. Box 61, Montgomery, Alabama 36101

245-246. C. C. Palmiter, Office of Radiation Programs, Environmental Protection Agency, 401 M Street SW, Washington, D. C. 20460

247. Jerry Cohen, Lawrence Livermore Laboratory, P. 0. Box 808, Livermore, California 94551

248. Daniel W. Wilson, Lawrence Livermore Laboratory, P. 0. Box 808, Livermore, California 94551

249. Todd V. Crawford, Savannah River Laboratory, E. I. du Pont de Nemours \& Company, Aiken, South Carolina 29801

250. Peter J. Mellinger, Environmental Safeguards Division, NUS Corporation, 4 Research Place, Rockville, Maryland 20850

251. Stephen Jinks, Institute of Environmental Medicine, New York University Medical Center, Long Meadow Road, Tuxedo, New York 10987

252. Jack G. Christian, Office of Radiation Programs, U. S. Environmental Protection Agency, $401 \mathrm{M}$ Street SW, Washington, D. C. 20460

253. Andre Bouville, United Nations, Scientific Committee on the Effects of Atomic Radiation, New York, New York 10016

254. Warren Donnelly, Library of Congress Legislative Reference Service, Washington, D. C. 20504

255. F. A. Gifford, Jr., Air Resources Atmospheric Turbulence and Diffusion Laboratory, NOAA, Oak Ridge, Tennessee 37830

256. Murray Calkins, National Environmental Research Center, Environmental Protection Agency, Cincinnati, Ohio 45268

257. DeVaughn R. Nelson, Directorate of Licensing, Environmental Project Branch No. 3, Mail Station 008, Washington, D. C. 20545

258. W. H. Ray, Office of Regulation, U. S. Atomic Energy Commission, Bethesda, Maryland 20545

259. Don F. Harmon, Office of Regulation, U. S. Atomic Energy Commission, Bethesda, Maryland 20545

260. J. K. Soldat, Pacific Northwest Laboratories, Battelle Memorial Institute, Richland, Washington 99352

261. David McCurdy, Ecology Section, Los Alamos Scientific Laboratory, P. 0. Box 1663, Los Alamos, New Mexico 87544

262-263. Technical Information Center, AEC, Oak Ridge, Tennessee

264. Research and Technical Support Division, ORO, Oak Ridge, Tennessee 37830

265. Patent Office, AEC, Oak Ridge, Tennessee 37830 